\title{
Evidence-based pharmacotherapy of obsessive-compulsive disorder
}

\author{
Naomi A. Fineberg ${ }^{1}$ and Tim M. Gale ${ }^{2}$ \\ ${ }^{1}$ Department of Psychiatry, Queen Elizabeth II Hospital, Welwyn Garden City, UK \\ ${ }^{2}$ Department of Psychology, University of Hertfordshire, Hatfield, UK
}

\begin{abstract}
Obsessive-compulsive disorder is a prevalent and disabling lifespan disorder. Clomipramine and the SSRIs have been found to be effective across the range of symptoms, both in acute and longer-term studies. Meta-analyses have reported a larger treatment effect for clomipramine relative to the SSRIs, but this is not supported by evidence from head-to-head comparator studies and, based on their superior safety and tolerability, SSRIs are the preferred option for long-term treatment in most cases. The treatment-effect is usually gradual and partial, and many patients fail to respond adequately to first-line treatment. Pharmacological options for refractory cases include switching SRI, increasing the dose, or augmenting with an antipsychotic agent. Novel strategies are under investigation for this highly morbid group. This paper reviews the key questions related to OCD pharmacotherapy, synthesizing evidence derived from randomized controlled trials, meta-analyses and consensus guidelines.
\end{abstract}

Received 12 November 2003; Reviewed 2 December 2003; Revised 11 January 2004; Accepted 18 January 2004

Key words: Obsessive-compulsive disorder, pharmacological treatment, review.

\section{Introduction}

Obsessive-compulsive disorder (OCD) is now recognized to be a common, treatable illness with a distinctive pathophysiology and pharmacology. Wide-ranging epidemiological surveys have repeatedly demonstrated high lifetime prevalence, amounting to $2-3 \%$ of the population worldwide under DSM-III and DSM-III-R criteria (Robins et al., 1984; Weissman et al., 1994). However only a fraction of sufferers present for treatment and the diagnosis is often missed. OCD is somewhat more common in women than men (ratio 1.5:1) and the mean age of onset is reported as $20 \mathrm{yr}$, with bimodal peaks at 12-14, and 20-22 yr (Rasmussen and Eisen, 1990). There is a high childhood incidence and, if untreated, OCD runs a fluctuating, unremitting course with the greatest prevalence in early-middle adult life. A substantial lifetime comorbidity with several DSM-IV Axis I and Axis II disorders have been identified (Hollander et al., 1998), including depression which supervenes in approximately two thirds of cases,

Address for correspondence: Dr N. A. Fineberg, Consultant Psychiatrist, Queen Elizabeth II Hospital, Howlands, Welwyn Garden City, Hertfordshire, AL7 4HQ, UK.

Tel.: + 44 (0)1707365085 Fax: + 44 (0)1707 365582

E-mail: naomi.fineberg@btinternet.com simple phobia $(22 \%)$, social phobia $(18 \%)$, eating disorder $(17 \%)$, alcohol dependence $(14 \%)$, panic disorder $(12 \%)$ and Tourette's syndrome (7\%; Pigott et al., 1994), and increased rates of suicidal behaviour. The costs of OCD to society, in terms of individual suffering, diminished human potential and lost revenue, are high (Hollander and Wong, 1998).

The systematic investigation of OCD has depended, to a large extent, on the introduction of universally accepted diagnostic criteria and the development of comprehensive and sensitive rating scales that measure small changes in symptoms, such as the 6- and 8-item scales (Montgomery and Montgomery, 1980; Thoren et al., 1980 respectively) derived from the Comprehensive Psychopathological Rating Scale (CPRS; Asberg et al., 1978) and the Yale-Brown Obsessive Compulsive Scale (YBOCS; Goodman et al., 1984). However, in spite of such advances, OCD remains poorly recognized and under-treated. Although surveys suggest the time lag between symptom onset and correct diagnosis is shortening, patients still wait an average of $17 \mathrm{yr}$ before appropriate treatment is initiated (Hollander and Wong, 1998). It is often only when depression supervenes that OCD sufferers present for treatment. At this point it is vital to the success of clinical intervention that the OCD is not overlooked. 
This review considers the evidence base for the pharmacological management of OCD based upon, wherever possible, randomized controlled trials (RCTs). Three fundamental clinical issues are addressed: (1) what are the first-line treatments? (2) how long should treatment continue? and (3) what is the preferred treatment for those who do not respond to first-line agents? Uncontrolled studies are cited where systematic data is lacking and meta-analyses are cited where adequate head-to-head comparator-studies do not exist. Expert consensus guidelines are considered and practical recommendations made for the clinical setting. A systematic search of electronic databases [EMBase (1974-date), MEDLINE (1966-date), PsychInfo (1987-date)] was run using combinations of the terms obsessive compulsive (randomised or control\$ or clinical trial $\$$ or placebo $\$$ or blind $\$$ ) and (systematic or review\$ or meta-analysis), as well as individual drug names. This was complemented by consulting with colleagues in the field and reviewing recent data presented at international, peer-reviewed symposia. Most published studies have investigated acute treatment of OCD, with a shortage of long-term and relapseprevention data. The results from a growing number of studies on children suggest they respond similarly to adults. There is a regrettable shortage of data on pharmacotherapy of OCD in the elderly.

The weight of evidence shows that OCD responds preferentially to drugs which powerfully inhibit the synaptic reuptake of serotonin, i.e. clomipramine and selective serotonin reuptake inhibitors (SSRIs). Drugs lacking potent SRI actions have not been effective in controlled studies. This selective pharmacological response has generated hypotheses about the role of serotonin in the aetiology of OCD but, so far, no unifying theory has emerged and the mechanisms by which SSRIs exert anti-obsessional benefits remain poorly understood (Fineberg et al., 1997). It is widely believed that OCD encompasses a heterogenous group of illnesses, and that other neurotransmitters are involved in its pathophysiology.

\section{First-line treatments for OCD}

\section{Clomipramine}

The first uncontrolled case series showing successful treatment with clomipramine appeared in the 1960s (Fernandez and Lopez-Ibor, 1967; Reynghe de Voxrie, 1968) and, by 1990, a collection of double-blind, placebo-controlled trials demonstrated conclusively that clomipramine is efficacious in OCD, both in the presence (Flament et al., 1985; Insel et al., 1983; Jenike et al., 1989; Marks et al., 1980; Mavissakalian et al., 1985; Thoren et al., 1980) and absence (Marks et al., 1988; de Veaugh-Geiss et al., 1989; Katz et al., 1990) of comorbid depression.

\section{Clomipramine in OCD without depression}

Early reports suggested that clomipramine may exert benefit on obsessional symptoms within depression, and it was unclear if this was an antidepressant effect, or a more specific effect on OCD. The first study of 'pure' OCD patients (Montgomery, 1980) employed a cross-over design with randomized allocation to 4-wk treatment, and a low fixed daily dose (75 $\mathrm{mg}$ ) to protect blinding. Early onset of action was detected on the 6-item CPRS-OC scale, with significant advantages over placebo at 1, 3, $4 \mathrm{wk}$ in the group comparison, and 2, 3, $4 \mathrm{wk}$ in the cross-over analysis, despite only 14 patients taking part. This finding was replicated by Marks et al. (1988), who reported efficacy over concurrent exposure therapy and placebo, and by Greist et al. (1990), who demonstrated clear efficacy using only 32 cases. Two multicentre studies of clomipramine, comprising 238 and 263 cases respectively, and where concomitant depression was excluded, have been published (see de Veaugh Geiss et al., 1989; and subsequently the Clomipramine Collaborative Study Group, 1991). Placebo response did not exceed $5 \%$ reduction in YBOCS total over $10 \mathrm{wk}$, with significant differences emerging for clomipramine groups at weeks $1-2$. The benefits of clomipramine, given in flexible doses up to $300 \mathrm{mg} / \mathrm{d}$, increased slowly and gradually after $1 \mathrm{wk}$ of treatment up to the 10 -wk end-point. The resulting $38 \%$ and $44 \%$ (respective) improvements in baseline OC ratings represented substantial improvement in emotional and social well-being. Another 10 -wk study by Katz et al. (1990) stratified patients by the Hamilton Depression Scale (Hamilton, 1960) scores. In the nondepressed subgroup, 134 patients improved significantly on the National Institute of Mental Health Global Obsessive Compulsive Scale (NIMH-OC) (Insel et al., 1983), nearing a $40 \%$ reduction of baseline score (cf. 129 on placebo who remained essentially unchanged).

\section{Clomipramine in OCD with depression}

Eight placebo-controlled studies have investigated clomipramine in OCD with comorbid depression. A 5-wk study by Thoren et al. (1980) comparing clomipramine to nortriptyline and placebo, showed significant improvement on the CPRS-OC scale for clomipramine over nortriptyline and placebo. In Insel 
et al.'s (1983) cross-over study $(n=12)$, clomipramine was superior to clorgyline and placebo at 4 and $6 \mathrm{wk}$. Moreover, Marks et al. (1980), showed significance at $4 \mathrm{wk}$ for clomipramine in 40 ritualizers although these findings relied on self-rated instruments. Further small studies by Mavissakalian et al. (1985) and Jenike et al. (1989) also showed significance for clomipramine (100-300 mg) over placebo.

The controlled study by Flament et al. (1985) was the first to demonstrate efficacy of a pharmacological treatment in childhood OCD. Nineteen children with primary OCD, aged 6-18 yr entered the 5-wk crossover study. A significant improvement in obsessional scores was seen for clomipramine (mean dose $141 \mathrm{mg} / \mathrm{d}$ ), and this was irrespective of baseline depression. Significant post-baseline improvements were also observed in the placebo group, suggesting that children may be susceptible to non-specific treatment effects. However, a positive study by de Veaugh-Geiss et al. (1992) on children and adolescents reported only an $8 \%$ improvement in the placebo group $(n=29)$ at the 8 -wk end-point, compared to $37 \%$ on clomipramine $(n=31)$, with significant differences evident from $3 \mathrm{wk}$.

Most of the above studies are small by today's standards but the pattern of results is highly consistent. Such consistency is rare in psychopharmacological research and, together, the results offer unequivocal support for the efficacy of clomipramine in OCD. They also reflect the special qualities of patients under investigation at that time. Most had long histories of stable, severe, untreated illness with few treatmentrefractory cases. The studies' power also depended on low placebo-response rates and these distinguish OCD from depression and other anxiety disorders where placebo-response rates are higher.

\section{SRIs compared to other antidepressants lacking strong serotonergic activity}

Clomipramine is distinguished from other tricyclics by its more powerful SRI activity, although its effects are not exclusively serotonergic. In the first crossover study comparing clomipramine with the noradrenergic tricyclic desipramine (Insel et al., 1985) the response to desipramine was indistinguishable from placebo, whereas clomipramine was superior. Failure of desipramine relative to clomipramine was seen more clearly in two cross-over studies in children (Leonard et al., 1988, 1991), and in later comparisons with SSRIs such as fluvoxamine (Goodman et al., 1990) and sertraline (Hoehn-Saric et al., 2000). Likewise, in studies comparing clomipramine with imipramine, the former was superior at 6 and 12 wk (Volavka et al., 1985). Antidepressant responses were reported in imipramine-treated patients (Foa et al., 1987), but while clomipramine exerted anti-obsessional benefits, imipramine did not. In a small, three-way study by Thoren et al. (1980), clomipramine was superior to placebo but nortriptyline was not; and in a small study by Ananth et al. (1981) there was a significant advantage for clomipramine but not amitriptyline, The small placebo-controlled cross-over study by Insel et al. (1983) found clomipramine to be superior to clorgyline in 13 patients. And although the study by Vallejo et al. (1992) was probably too small to discriminate between phenelzine and clomipramine, Jenike et al. (1997) demonstrated a significant advantage for fluoxetine over phenelzine, the latter being indistinguishable from placebo. No study to date has demonstrated a convincing advantage for a monoamine oxidase inhibitor (MAOI) over placebo in OCD.

In some studies, comparator agents may have shown some anti-obsessional benefit, but the effect is consistently weaker than that of SRIs. Demonstrating a significant difference between active treatments usually requires a large sample size, so the fact that several small studies show superiority for SRIs strongly suggests that non-SRIs have little, if any, efficacy in OCD.

\section{SSRIs}

Although clomipramine is a powerful SRI, it has an active metabolite with strong noradrenergic properties. That the more highly selective SSRIs are also beneficial, showing a similar slow, incremental effect, suggests their anti-obsessional actions are related to this pharmacological property. Early promising reports suggesting efficacy for zimelidine were curtailed by the withdrawal of the drug for safety reasons.

\section{Placebo-controlled studies of fluvoxamine}

Perse et al. (1987) reported a double-blind cross-over study of fluvoxamine in 20 patients. Efficacy was evident after $8 \mathrm{wk}$, based on 16 completers. Fluvoxamine also showed superiority over placebo in the 8- and 24-wk analysis by Cottraux et al. (1990), in spite of concurrent exposure therapy in the placebo group, thereby emphasizing the strength of the drug effect relative to psychotherapy. The study has been criticized for not including an intent-to-treat (ITT) analysis and for relying on behavioural ratings for the OCD. Goodman et al. (1989) demonstrated similar response profiles in depressed and non-depressed OCD patients with significant placebo-referenced 
improvement on the YBOCS from week 2 onwards. Similar results were reported by Jenike et al. (1990a), although significant differences appeared only at week 10. The multi-centre study by Goodman et al. (1996), looking at two groups of 78 patients receiving either $10 \mathrm{wk}$ of fluvoxamine (100-300 mg) or placebo, confirmed superiority for fluvoxamine on all outcome measures from week 4 onwards. Obsessions and compulsions both improved with a possible earlier benefit for obsessions. Only 10 cases discontinued because of side-effects.

Another multicentre study by Hollander et al. (2003a) compared 127 patients on flexible, once-daily doses of controlled-release (CR) fluvoxamine (100$300 \mathrm{mg}$ ), with 126 on placebo. Fluvoxamine CR was superior in decreasing YBOCS scores from as early as week 2. By the 12-wk end-point fluvoxamine CRtreated individuals showed a $32 \%$ improvement, compared to $21 \%$ on placebo, with significantly greater improvements on Clinical Global Impression-Severity (CGI-S), Clinical Global Impression-Improvement (CGI-I) and responder analyses. Remission was defined as either a YBOCS total score of $<16$, or a subscore of $<8$, and remission rates for fluvoxamine CR were $44 \%$ and $18 \%$ respectively. In the fluvoxaminetreated group, 19\% (cf. 6\% placebo) withdrew early through adverse effects (mainly nausea, insomnia, somnolence, dizziness and diarrhoea).

Riddle et al. (2001) reported the first RCT of fluvoxamine (50-200 mg) in 120 children aged 817 yr. Improvement, on the Children's Yale-Brown Obsessive-Compulsive Scale (C-YBOCS), was superior to placebo from weeks $1-6$ and at the $10-w k$ end-point. Only three patients on fluvoxamine and one on placebo withdrew through adverse effects. This finding supports the rapid efficacy and tolerability of fluvoxamine in childhood OCD.

\section{Placebo-controlled studies of sertraline}

Jenike et al. (1990b) found no group differences in a study comparing sertraline $(n=10)$ and placebo $(n=9)$, although this study was arguably underpowered. Chouinard et al. (1990) demonstrated superiority for flexible doses of sertraline (50-200 mg) on the YBOCS and NIMH-Global OC scale, but not on the Maudsley Obsessive-Compulsive Inventory (Hodgson and Rachman, 1977), suggesting that the latter may lack sensitivity for monitoring clinical change. Kronig et al. (1999) replicated this work in a larger sample, demonstrating superiority for sertraline (50-200 $\mathrm{mg}, n=86)$ over placebo $(n=81)$ as early as $3 \mathrm{wk}$. Ten per cent of the sertraline group and $5 \%$ of the placebo group discontinued because of sideeffects. The subsequent fixed-dose study by Greist et al. (1995a), which was hampered by a strong placebo response, showed efficacy on the YBOCS for pooled sertraline $(50-200 \mathrm{mg}, n=240)$ at week 2 onwards compared to placebo $(n=84)$. However, at the 12-wk end-point, almost as many in the placebo group $(30 \%)$ were much or very much improved compared to those on sertraline (39\%). March et al. (1998) evaluated the efficacy of sertraline, titrated up to $200 \mathrm{mg}$, in a cohort of 107 children and 80 adolescents, finding a significant advantage on the CYBOCS over placebo as early as $3 \mathrm{wk}$. Insomnia, nausea, agitation and tremor were over-represented in the drug-treated condition and $13 \%$ of sertraline patients discontinued early because of adverse effects (cf. 3\% placebo). Cardiovascular parameters were systematically monitored and showed no clinically meaningful abnormalities, suggesting that sertraline is safe up to doses of $200 \mathrm{mg}$ in children (Wilens et al., 1999).

\section{Placebo-controlled studies of fluoxetine}

Fluoxetine has also been extensively investigated in OCD. Two multicentre studies benefited from a design that allowed comparison of different fixed doses. In the 8-wk study by Montgomery et al. (1993), the 20-mg dose $(n=52)$ fared no better than placebo $(n=56)$, while the $40-\mathrm{mg}$ dose $(n=52)$ was superior on the responder analysis and the 60-mg dose $(n=54)$ superior both on reduction of YBOCS scores and responder rate. Side-effects were low and $<6 \%$ withdrew early because of them. In the larger, longer study by Tollefson et al. (1994), all fixed doses of fluoxetine emerged as superior to placebo by the 13-wk end-point, but there was a trend towards superiority for the 60-mg dose on the YBOCS analysis. Side-effects on fluoxetine included nausea, dry mouth, tremor and sexual problems. A meta-analysis of separate study data showed no association between fluoxetine and suicidality in OCD (Beasley et al., 1992). The placebo-controlled study by Jenike et al. (1997) investigated doses of fluoxetine up to $80 \mathrm{mg}$, and included a comparison with the MAOI phenelzine. Fluoxetine $(n=23)$ was superior to placebo $(n=21)$ and phenelzine $(n=20)$, which did not differentiate from placebo.

Three studies have looked at fluoxetine in childhood OCD, all showing some level of superiority over placebo. Riddle et al.'s (1992) cross-over study on 14 children used fixed doses of $20 \mathrm{mg}$. A significant advantage was observed on the CGI but not C-YBOCS, 
which showed a $44 \%$ improvement after 8 -wk treatment, compared to $27 \%$ on placebo. Behavioural activation occurred as an adverse effect in a few children, and one left the study early because of suicidal ideation. The authors considered these side-effects to be dose-related, advocating initiating treatment at lower doses. Geller et al. (2001) took a larger cohort, titrating doses upwards from 10 to $60 \mathrm{mg}$ over $13 \mathrm{wk}$, according to clinical response. Fluoxetine was superior to placebo on the C-YBOCS from week 6 and was well tolerated across all doses, with similar drop-out rates from adverse events on drug (8.5\%) and placebo. Leibowitz et al. (2002) extended the dose range to $80 \mathrm{mg}$ after the first $6 \mathrm{wk}$ in a trial spanning $7 \mathrm{yr}$. After $8 \mathrm{wk}$, responders could continue double-blind treatment for a further $8 \mathrm{wk}$. Fluoxetine's effects were slow to develop, and superiority over placebo did not emerge until after $8 \mathrm{wk}$. No patient withdrew because of adverse effects.

\section{Placebo-controlled studies of paroxetine}

Positive results from a fixed-dose study reported in poster form by Wheadon et al. (1993) were confirmed in a multinational study by Zohar and Judge (1996), which included clomipramine as a comparator agent. Paroxetine, given in doses up to $60 \mathrm{mg}(n=201)$, was significantly more effective than placebo $(n=99)$ on all a-priori efficacy measures, and of comparable efficacy to clomipramine $(50-250 \mathrm{mg}, n=99)$. Only $9 \%$ of paroxetine-treated patients withdrew because of sideeffects (mainly asthenia, headache, dry mouth and nausea) compared to $6 \%$ given placebo. In a large trial of 348 OCD patients, Hollander et al. (2003b) tested paroxetine in fixed doses $(20,40,60 \mathrm{mg})$ with placebo. Respective YBOCS score reductions were 16, 25, 29 and $13 \%$ in the acute phase of the study. Both higher doses were significantly different from placebo by week 6 and from the 20-mg dose by week 3 . Paroxetine was well tolerated at all doses.

\section{Placebo-controlled studies of citalopram}

The multinational placebo-controlled study by Montgomery et al. (2001) showed efficacy for fixed doses of $20 \mathrm{mg}(n=102), 40 \mathrm{mg}(n=98)$ and $60 \mathrm{mg}$ citalopram $(n=100)$ compared to placebo $(n=101)$. A significant reduction in baseline YBOCS score was seen from week 3 for the 60-mg group, and from weeks 7-12 for other doses. Citalopram was well tolerated $(4 \%$ withdrew through adverse effects; mainly nausea, headache, fatigue, insomnia) and improved psychosocial disability on the Sheehan Disability Scale (Sheehan et al., 1996). To date, there are no studies relating to the active s-isomer, escitalopram in OCD.

\section{Changes in study populations have affected treatment studies}

The data on SSRIs provides conclusive evidence of efficacy in OCD. The success of clomipramine and SSRIs has led to their rapid acceptance as first-line treatments, and it is increasingly difficult for specialist research centres to recruit patients who are not already receiving one of these pharmacotherapies. This has compromised the recruitment of treatment-naïve patients in more recent studies of SSRIs, where greater numbers of treatment-refractory individuals have been included. Moreover, exclusion of comorbid depression has reduced the numbers of severely ill individuals at baseline. Accordingly, the magnitude of the observed treatment effect has diminished from $40-50 \%$ average reduction in baseline scores in the clomipramine studies, to around $30 \%$ in the later SSRI studies. Between $32 \%$ and $65 \%$ of the SSRItreated study participants showed a clinically meaningful improvement using the various recognized criteria for clinical response. Table 1 summarizes the rates of clinical response in those studies that report them. Furthermore, increased placebo-response rates, in some cases exceeding $20 \%$ improvement in baseline scores, have also been observed in more recent studies, probably resulting from inclusion of milder, atypical cases, some of whom undergo spontaneous remission. The rise in the placebo response rate cautions against drawing conclusions about efficacy from open, naturalistic reporting, and emphasizes the importance of controlled investigation. Finally, the application of increasingly stringent inclusion criteria in recent studies, often driven by requirements of regulatory authorities, may well contribute to the changing pattern of response rates, since treatment groups are less heterogeneous. By contrast, response rates in general psychiatry clinics are probably closer to the original clomipramine results. The net effect of these changes has been to reduce the statistical power of the studies, so that larger numbers are now needed to test the efficacy of new treatments. Meta-analyses of existing studies can, to some extent, compensate by pooling data, but if they fail to take these changes into account they may be misleading.

\section{Meta-analyses of SRIs in OCD}

Meta-analyses combine data from separate studies using specific rules and provide a more objective and quantifiable measures of treatment-effect size than 
Table 1. Rates of clinical response in placebo-controlled studies of SSRIs for patients with OCD

\begin{tabular}{|c|c|c|c|c|c|}
\hline \multirow[b]{2}{*}{ Study } & \multicolumn{4}{|c|}{ Definition of clinical response } & \multirow[b]{2}{*}{$\begin{array}{l}\text { Drug } \\
\text { (duration, wk) }\end{array}$} \\
\hline & $\begin{array}{l}\text { Much or very } \\
\text { much improved } \\
\text { on CGI-I } \\
\text { (Criterion A) }\end{array}$ & $\begin{array}{l}>25 \% \text { improved } \\
\text { on baseline YBOCS } \\
\text { (Criterion B) }\end{array}$ & $\begin{array}{l}>35 \% \\
\text { improved } \\
\text { on baseline } \\
\text { YBOCS }\end{array}$ & $\begin{array}{l}\text { Criteria } \\
\text { A \& B }\end{array}$ & \\
\hline Goodman et al. (1989) & $9 / 21$ & & & & Fluvoxamine (8) \\
\hline Goodman et al. (1996) & $33.3 \%$ & & & & Fluvoxamine (10) \\
\hline Hollander et al. (2003a) & $34 \%$ from graph & $63 \%$ & $45 \%$ & & Fluvoxamine CR (12) \\
\hline Riddle et al. (2001) & & $42 \%$ (C-YBOCS) & & & Fluvoxamine (10) \\
\hline Kronig et al. (1999) & $41 \%$ & & & & Sertraline (12) \\
\hline Greist et al. (1995a) & $38.9 \%$ & & & & Sertraline (12) \\
\hline March et al. (1998) & $42 \%$ & & & & Sertraline (12) \\
\hline \multirow[t]{3}{*}{ Montgomery et al. (1993) } & & & & $36 \%$ & Fluoxetine 20 mg (8) \\
\hline & & & & $48 \%$ & Fluoxetine 40 mg (8) \\
\hline & & & & $47 \%$ & Fluoxetine 60 mg (8) \\
\hline \multirow[t]{3}{*}{ Tollefson et al. (1994) } & & & $32 \%$ & & Fluoxetine 20 mg (13) \\
\hline & & & $34 \%$ & & Fluoxetine 40 mg (13) \\
\hline & & & $35 \%$ & & Fluoxetine $60 \mathrm{mg}$ (13) \\
\hline Geller et al. (2001) & $55 \%$ & & & & Fluoxetine (13) \\
\hline Leibowitz et al. (2002) & $57 \%$ & & & & Fluoxetine (16) \\
\hline \multirow[t]{2}{*}{ Zohar and Judge (1996) } & $55.1 \%$ & & & & Paroxetine (12) \\
\hline & $55.3 \%$ & & & & Clomipramine (12) \\
\hline \multirow[t]{3}{*}{ Montgomery et al. (2001) } & $57.4 \%$ & & & & Citalopram $20 \mathrm{mg}$ (12) \\
\hline & $52 \%$ & & & & Citalopram $40 \mathrm{mg}$ (12) \\
\hline & $65 \%$ & & & & Citalopram $60 \mathrm{mg} \mathrm{(12)}$ \\
\hline
\end{tabular}

narrative reviews. However, problems may arise in controlling for between-study differences such as dose, duration, blindness, method of assessment and population differences, so results must be viewed cautiously (Pigott and Seay, 1999). In short, metaanalyses cannot substitute for high-quality head-tohead comparator trials.

Meta-analyses of existing OCD studies all suggest superior efficacy for clomipramine over SSRIs. An analysis by Jenike et al. (1990a) of their work on SSRIs showed that efficacy correlated negatively with serotonin selectivity. Stein et al. (1995) examined effect sizes for studies that employed validated rating scales and were of at least $6 \mathrm{wk}$ duration. However, although the effect size for clomipramine was larger than that of comparators, several methodological and statistical shortcomings were acknowledged, which limit the conclusions drawn. Piccinelli et al.'s (1995) meta-analysis related exclusively to doubleblind RCTs of clomipramine and SSRIs, using YBOCS or NIMH-OC scales. All treatments were significantly superior to placebo, but clomipramine was associated with significantly greater mean YBOCS reduction
(61\%) compared to fluoxetine $(28.5 \%)$, fluvoxamine $(28 \%)$, and sertraline $(22 \%)$ with no significant difference between individual SSRIs. The authors concluded that large-scale controlled comparator studies are needed to draw firmer conclusions about relative efficacy. Greist et al. (1995c) reported on data from four multi-centre, placebo-controlled studies of clomipramine, fluoxetine, fluvoxamine and sertraline. Clomipramine was significantly more effective than SSRIs, which did not differ in calculated effect size using the YBOCS. Whereas drop-out rates associated with adverse effects were similar across all groups $(8,12,15$ and $10 \%$ respectively), withdrawal from all causes was significantly lower in the clomipramine group.

Abramowitz (1997) investigated effect sizes of SRIs and psychological interventions in RCT data. Using clinician ratings, clomipramine was again superior to fluvoxamine, fluoxetine and sertraline (in decreasing order), and side-effect contrast was significantly correlated with effect size. Abramowitz suggested the apparent supremacy of clomipramine may, in part, be caused by unblinding because it has more noticeable 
side-effects. Kobak et al. (1998) extended the procedure to look at all available studies relating to SRIs and exposure therapy, regardless of publication mode and methodology. Data were analysed before and after attempts to control for methodological variables, such as year of publication and experimental design. The results were consistent with previous meta-analyses, inasmuch as clomipramine had the largest effect size compared to all the SSRIs apart from fluoxetine. However, after attempts to control for methodological variables, clomipramine was not significantly more effective than fluoxetine or fluvoxamine, but was still superior to other SSRIs. In their analysis of head-to-head comparisons, however, there was no significant difference between SRIs. The authors remarked on the consistency with which meta-analyses had favoured clomipramine over more selective SRIs. In spite of its less favourable side-effect profile, the drop-out rate for clomipramine was no different from the other SRIs. As predicted, year of publication was negatively correlated with treatment effect-size. These authors also postulated several additional biases in favour of clomipramine; for example, patients may have been more willing to continue on clomipramine, in spite of side-effects, because they inferred they were receiving the active drug, particularly when no other known alternatives were available. The unblinding effect may also have biased patients' and clinicians' assessment of improvement. This paper also acknowledged that its findings were not supported by the evidence from head-to-head trials.

Ackerman and Greenland's (2002) meta-analysis attempted to quantify characteristics of published trials that might account for differences in effect size. Although they used different techniques, their findings broadly agreed with previous analyses. The considerable heterogeneity across studies appeared to be associated with factors such as year of publication, length of single-blind pre-randomization period, length of trial and severity of OCD, and confirmed the recent rise in placebo-response rates. They concluded that the superiority of clomipramine in placebocontrolled trials persisted after controlling for these factors, but that there was no difference in studies comparing clomipramine directly with SSRIs.

Geller et al. (2003a) performed the first metaanalysis on pharmacotherapy for childhood OCD. Twelve trials were considered and the results were consistent with the adult literature, showing modest but significant advantages for all SRIs over placebo, and superiority for clomipramine over SSRIs. SSRIs were more or less comparable and the findings were not dependent on publication date or placeboresponse rate. The authors noted an absence of headto-head studies and recommended that clomipramine should not generally be used first-line in children because of its side-effect profile.

\section{Direct comparison of SRIs in OCD}

Thus far, only two controlled studies have compared the relative efficacy of different SSRIs, and the results are inconclusive. The single-blind study by Mundo et al. (1997a) that failed to detect differences between fluvoxamine, paroxetine and citalopram, was undoubtedly underpowered with only 10 patients per group. Bergeron et al. (2001) compared 77 patients on sertraline with 73 on fluoxetine, under double-blind conditions. At the 24-wk end-point, no significant difference was seen on primary efficacy measures, but there was a non-significant trend toward an earlier effect in the sertraline group, and a higher number of sertraline patients reached remission, defined as a CGI-I score of $\leqslant 2$ and a YBOCS score of $\leqslant 11$. In conjunction with meta-analysis data, these results do not support the superior efficacy of any one SSRI. The selection of a particular compound should, therefore, take account of other factors, such as possible interactions with other drugs being prescribed. In this respect, fluoxetine, paroxetine and to a much lesser extent sertraline, inhibit the P450 isoenzyme CYP2D6 which metabolizes tricyclic antidepressants, antipsychotics, anti-arrythmics and beta-blockers, whereas fluvoxamine inhibits both CYP1A2 and CYP3A4, which eliminate warfarin, tricyclics, benzodiazepines and some anti-arrhythmics. Citalopram is relatively free from hepatic interactions. Fluoxetine has a long half-life, and has fewer discontinuation effects, which can be advantageous for patients who forget to take their medication.

Whereas meta-analyses consistently report a smaller effect size for SSRIs relative to clomipramine, many head-to-head studies demonstrate equivalent efficacy (Table 2). While many of these were underpowered (Montgomery et al., 1990), the trial by Bisserbe et al. (1997) was large enough to detect a significant advantage for sertraline. However the advantage, apparent for certain measures in the ITT analysis, was not clear-cut. Another smaller study found an advantage for clomipramine over fluoxetine (40 mg) on secondary outcome measures (Lopez-lbor et al., 1996). The larger study first presented by Rouillon (1998; see also Mundo et al., 2001) showed equivalent efficacy for clomipramine and SSRI on all visits and measures. In the comparator study by 
Table 2. Controlled studies comparing SSRIs with clomipramine (CMI)

\begin{tabular}{|c|c|c|c|c|}
\hline \multirow[b]{2}{*}{ Drug and study } & \multirow[b]{2}{*}{$n$} & \multirow[b]{2}{*}{ Design } & \multicolumn{2}{|l|}{ Outcome } \\
\hline & & & Efficacy & Tolerability \\
\hline \multicolumn{5}{|l|}{ Fluoxetine (FLX) } \\
\hline Pigott et al. (1990) & 11 & $\begin{array}{l}\text { CMI (50-250 mg) vs. FLX } \\
(20-80 \mathrm{mg})\end{array}$ & $\begin{array}{l}\mathrm{CMI}=\mathrm{FLX} \\
\mathrm{CMI}=\mathrm{FLX} \text { on } \\
\text { primary criterion }\end{array}$ & $\mathrm{FLX}>\mathrm{CMI}$ \\
\hline Lopez-Ibor et al. (1996) & 30 vs. 24 & CMI (150 mg) vs. FLX (40 mg) & $\begin{array}{l}\text { CMI }>\text { FLX on } \\
\text { other criteria }\end{array}$ & $\mathrm{FLX}=\mathrm{CMI}$ \\
\hline \multicolumn{5}{|l|}{ Fluvoxamine (FLV) } \\
\hline Smeraldi et al. (1992) & 10 & CMI (200 mg) vs. FLV (200 mg) & $\mathrm{CMI}=\mathrm{FLV}$ & $\mathrm{FLV}=\mathrm{CMI}$ \\
\hline Freeman et al. (1994) & 30 vs. 34 & $\begin{array}{l}\text { CMI (150-250 mg) vs. FLV } \\
(150-250 \mathrm{mg})\end{array}$ & $\mathrm{CMI}=\mathrm{FLV}$ & $\begin{array}{r}\text { FLV }>\text { CMI (on } \\
\text { severe effects) }\end{array}$ \\
\hline Koran et al. (1996) & 42 vs. 37 & $\begin{array}{l}\text { CMI (100-250 mg) vs. FLV } \\
(100-250 \mathrm{mg})\end{array}$ & $\mathrm{CMI}=\mathrm{FLV}$ & $\mathrm{FLV}=\mathrm{CMI}$ \\
\hline Milanfranchi et al. (1997) & 13 vs. 13 & $\begin{array}{l}\text { CMI (50-300 mg) vs. FLV } \\
(50-300 \mathrm{mg})\end{array}$ & $\mathrm{CMI}=\mathrm{FLV}$ & $\mathrm{FLV}=\mathrm{CMI}$ \\
\hline Rouillon (1998) & 105 vs. 112 & $\begin{array}{l}\text { CMI (150-300 mg) vs. FLV } \\
(150-300 \mathrm{mg})\end{array}$ & $\mathrm{CMI}=\mathrm{FLV}$ & FLV $>$ CMI \\
\hline \multicolumn{5}{|l|}{ Paroxetine (PAR) } \\
\hline Zohar and Judge (1996) & $\begin{array}{l}99 \text { vs. } 201 \\
\text { vs. } 99\end{array}$ & $\begin{array}{l}\text { CMI (50-250 mg) vs. PAR } \\
\text { (20-60 mg) vs. Placebo }\end{array}$ & $\begin{array}{l}\text { CMI }>\text { Placebo } \\
\text { PAR }>\text { Placebo }\end{array}$ & $\mathrm{PAR}>\mathrm{CMI}$ \\
\hline \multicolumn{5}{|l|}{ Sertraline (SER) } \\
\hline Bisserbe et al. (1997) & 82 vs. 86 & $\begin{array}{l}\text { CMI (50-200 mg) vs. SER } \\
(50-200 \mathrm{mg})\end{array}$ & $\mathrm{SER}=\mathrm{CMI}$ & SER $>$ CMI \\
\hline \multicolumn{5}{|l|}{ Citalopram (CIT) } \\
\hline Pidrman and Tuma (1998) & 24 & CIT vs. CMI & $\mathrm{CIT}=\mathrm{CMI}$ & $\mathrm{CIT}=\mathrm{CMI}$ \\
\hline
\end{tabular}

Zohar and Judge (1996) paroxetine and clomipramine showed similar placebo-referenced efficacy at weeks 6, 8 and 12. Paroxetine was superior to placebo on depression ratings whereas clomipramine was not. Response was defined as $25 \%$ or more improvement in baseline YBOCS scores and at end-point, 55\% of both paroxetine- and clomipramine-treated patients met this criterion, compared to $35 \%$ in the placebo group.

\section{Improved tolerability favours SSRIs}

Altogether, the evidence does not appear strong enough to support superior efficacy of clomipramine over SSRIs. In the face of equivalence, choice of SRI depends greatly on the side-effect profile of the compound. An important advantage of the SSRIs, compared to clomipramine, lies in their improved acceptability and tolerability (Table 2). In the comparator study of Zohar and Judge (1996), the drop-out rate from adverse effects on clomipramine (approx. $17 \%$ ) was consistently higher than for paroxetine
(9\%), and Rouillon (1998) reported that clomipramine was associated with significantly more early withdrawals associated with side-effects than fluvoxamine. Moreover, in Bisserbe et al.'s (1997) ITT analysis, it was concluded that superior tolerability of sertraline over clomipramine explained its greater benefit.

The risk of dangerous side-effects such as convulsions (occurring in up to $2 \%$ on clomipramine, compared to $0.1-0.5 \%$ on high-dose SSRIs), cardiotoxicity and cognitive impairment is substantially lower with SSRIs. Clomipramine shares anticholinergic side-effects associated with tricyclics including dry mouth, constipation and blurred vision, and is lethal in overdose. All SRIs are associated with impaired sexual performance but clomipramine (up to $80 \%$ cases, Monteiro et al., 1987) appears more problematic than SSRIs (up to 30\% cases). SSRIs are responsible for more asthenia, insomnia, and nausea. Maina et al. (2003a) reported clinically relevant weight gain in approx. $14.5 \%$ cases (mainly females) over 30 months of open SRI monotherapy, with clomipramine 
Table 3. Placebo-controlled comparator studies of fixed-doses of SSRI

\begin{tabular}{|c|c|c|c|c|}
\hline Drug and studies & Fixed dose & $n$ & Duration & $\begin{array}{l}\text { Positive } \\
\text { dose-response } \\
\text { relationship? }\end{array}$ \\
\hline \multicolumn{5}{|l|}{ Fluoxetine } \\
\hline Montgomery et al. (1993) & $20 / 40 / 60 \mathrm{mg}$ & 214 & 8 wk & $Y_{e s}{ }^{a}$ \\
\hline Tollefson et al. (1994) & $20 / 40 / 60 \mathrm{mg}$ & 355 & 13 wk & No \\
\hline \multicolumn{5}{|l|}{ Sertraline } \\
\hline Greist et al. (1995b) & $50 / 100 / 200 \mathrm{mg}$ & 324 & $12 \mathrm{wk}$ & No \\
\hline \multicolumn{5}{|l|}{ Paroxetine } \\
\hline Wheadon et al. (1993) & $20 / 40 / 60 \mathrm{mg}$ & 348 & $12 \mathrm{wk}$ & Yes \\
\hline Hollander et al. (2003b) & $20 / 40 / 60 \mathrm{mg}$ & 348 & $12 \mathrm{wk}$ & Yes \\
\hline \multicolumn{5}{|l|}{ Citalopram } \\
\hline Montgomery et al. (2001) & $20 / 40 / 60 \mathrm{mg}$ & 352 & $12 \mathrm{wk}$ & No \\
\hline
\end{tabular}

${ }^{a}$ Marginally significant benefit for medium and higher doses on primary analysis

(total YBOCS, $p=0.059)$; significant on 'responder' analysis $(p<0.05)$.

producing more weight gain than sertraline and fluoxetine.

The concept of a 'gold-standard' drug for OCD is, perhaps, misleading. According to YBOCS analyses, SSRIs appear equally effective at relieving obsessional thoughts and compulsive rituals. Their improved safety and tolerability offer considerable benefits for the long-term treatment of OCD, and indicate that the SSRIs should usually be considered the treatments of choice, with clomipramine reserved for those who cannot tolerate or who have failed to respond to them.

\section{Expert consensus guidelines for $\mathrm{OCD}$}

Expert consensus has a role in complementing and supplementing empirical evidence. By synthesizing combined views on best practice, a broader range of pertinent clinical questions can be addressed. Moreover, such opinions reflect experience with a range of cases and not just the highly selected groups that meet study criteria. The Expert Consensus Panel for OCD (March et al., 1997) comprised 65-100 worldwide experts and the guidelines present specific judgements on a comprehensive range of issues relating to pharmacological and psychological treatments. The guidelines recommended initial treatment either with cognitive behaviour therapy (CBT) alone or in conjunction with an SRI. $\dagger$ Although the guidelines

$\uparrow$ Available evidence suggests that exposure therapy is associated with similar rates of improvement as pharmacotherapy, and that combining the two forms of treatment is beneficial, although properly controlled head-to-head studies have not been performed. A review of behaviour therapy is beyond the scope of this paper. did not distinguish between clomipramine and SSRIs, improved tolerability of the latter was acknowledged. Combined CBT and medication was preferred by experts in terms of speed, efficacy, durability, tolerability and acceptability, and was thought the best approach for most patients. Inclusion of medication should depend on illness severity and age. More recently a smaller group of members of the World Council on Anxiety met to agree recommendations for long-term treatment (Greist et al., 2003).

\section{What is the most effective dose?}

Traditionally, OCD has been thought to require higher doses of medication than depression and anxiety. Head-to-head studies comparing different fixed doses of active drug with placebo are needed to examine this issue. Clomipramine has not been tested in this way. Whereas the single-dose studies showed efficacy for relatively low fixed daily doses (75 and $125 \mathrm{mg}$ ) compared to placebo, most studies used flexible doses titrated towards the upper end of the range (200-300 mg/d). Similarly, fluvoxamine was found to be effective in doses ranging from $150-300 \mathrm{mg} / \mathrm{d}$.

Fluoxetine, paroxetine and sertraline have each been investigated in a series of multiple fixed doses (Table 3 ). In the case of paroxetine, a positive doseresponse relationship was clearly demonstrated; in two studies a 40-mg and 60-mg dose showed efficacy while a 20-mg dose did not (Hollander et al., 2003b; Wheadon et al., 1993). Similar results are seen for fluoxetine: whereas all three fixed doses (20, 40, $60 \mathrm{mg} / \mathrm{d}$ ) were effective, the greatest benefit was seen in patients receiving the highest dose, although 
this did not reach statistical significance. Adverse effects appeared to be dose related, with no differences between 20-mg and placebo groups, compared to $18.5 \%$ early withdrawal in the $60-\mathrm{mg}$ group (Tollefson et al., 1994). A meta-analysis of the contemporaneous grouped data showed that the 60-mg dose was significantly more effective than $20 \mathrm{mg}$ (Wood et al., 1993). A smaller fixed dose comparison of 20, 40 and $60 \mathrm{mg}$ fluoxetine produced clearer findings. In this study the 40 - and $60-\mathrm{mg}$ doses were effective, but the 20-mg dose was not (Montgomery et al., 1993). The existence of a dose-response relationship is less clear-cut in the case of sertraline and citalopram. In a multiple fixed-dose study of sertraline (Greist et al., 1995b), the 50- and 200-mg doses were superior to placebo, whereas the 100-mg dose was not, possibly because of increased withdrawal rates in the 100-mg group. A smaller study (Ushijima et al., 1997) suggested that a dose-response relationship exists for sertraline as well. In the fixed-dose study of citalopram (Montgomery et al., 2001), a numerical advantage was seen for higher dose-levels, and a significant reduction in baseline YBOCS score was seen from week 3 in the $60-\mathrm{mg}$ group, compared to weeks 7-12 in the other two groups. However, these differences did not reach statistical significance.

These mixed results suggest that higher doses (e.g. $60 \mathrm{mg}$ paroxetine, fluoxetine, citalopram; $200 \mathrm{mg}$ sertraline) produce better anti-obsessional efficacy. Controlled studies demonstrate efficacy and tolerability for doses as high as $80 \mathrm{mg}$ fluoxetine (Jenike et al., 1997; Leibowitz et al., 2002) and $300 \mathrm{mg}$ clomipramine (de Veaugh-Geiss et al., 1989). The expert guidelines advocate treatment at moderate dose-levels in most cases, only titrating upwards to the maximum after a period of assessment.

\section{Strategies for dose titration in OCD}

Acute studies of SRIs show a slow, gradual treatment effect and, unlike panic disorder, exacerbation of anxiety is rare in the first days of treatment. Improvements can take several weeks to become established, irrespective of dose, and patients should be warned about this from the outset. Individuals with OCD are notoriously poor at recognizing their own improvements, and it is useful to enlist the help of informants to report early signs of improvement. Observer-rated scales may also detect small improvements in a clinical setting, although in some cases observable benefits may not appear for several months. These cases can be extremely challenging, with pressure on the clinician to change treatments or escalate doses prematurely.
Given the dose-response data, there are clear grounds for titrating doses upwards, but the clinician needs to strike a delicate balance between speed of increase and tolerability. Fast upwards titration may produce earlier responses, but the long-term benefits of this approach are unclear. A single-blind study compared rapid dose escalation with sertraline to $150 \mathrm{mg}$ over $5 \mathrm{~d}$, with slower dose escalation over $15 \mathrm{~d}$, and found a significant difference in favour of the rapid titration group at weeks 4 and 6, but this advantage disappeared thereafter (Bogetto et al., 2002). The study was too small to discern differences in tolerability. In another study, pulse loading with intravenous clomipramine produced a large and rapid decrease in obsessive symptoms, but oral pulse loading did not, and the early advantages were not sustained over treatment (Koran et al., 1997). The arguments for slower dose increases may be more persuasive, particularly in children and the elderly. Early SSRIrelated adverse effects such as nausea and agitation can be ameliorated by slowly titrating upwards over weeks and months. Longer-term side-effects such as sleep disturbance and headache are also dose-related, and need to be monitored. Sexual dysfunction is a common cause of drug discontinuation, and, if necessary, strategies such as dose reduction, short drug-holidays or use of drugs with restorative potency (e.g. nefazodone, viagra, mianserin; Aizenberg et al., 1999) can be considered in stable cases.

The expert guidelines recommend continuing treatment at average dose levels for $4-8 \mathrm{wk}$. If there are no signs of improvement at that point, they suggest proceeding to the maximum licensed dose. In the case of partial improvement, the guidelines suggest waiting longer for the effect to increase (5-9 wk) before titrating the dose upwards. When at the highest dose it is best to continue for at least 3 months (in some cases longer periods are required) to allow the treatment effect time to develop.

\section{SRIs are the treatment of choice in comorbid depression}

Moderate levels of depression do not interfere with the anti-obsessional response (Zohar and Judge, 1996). However, comorbid depression has received relatively little attention because most studies have excluded depressed individuals. Clomipramine, fluvoxamine and sertraline have been compared with desipramine in groups where comorbid depression was included. In the study by Hoehn-Saric et al. (2000) patients were specifically selected for the presence of significant depression. In general, comorbid depression 
Table 4. Placebo-controlled studies of long-term treatments for patients with OCD

\begin{tabular}{|c|c|c|c|c|}
\hline Study & Active treatment & $n$ & $\begin{array}{l}\text { Duration } \\
\text { (wk) }\end{array}$ & Outcome \\
\hline Cottraux et al. (1990) & $\begin{array}{l}\text { Fluvoxamine }+ \\
\text { exposure }^{\mathrm{a}}\end{array}$ & $\begin{array}{l}50 \\
44 \\
37\end{array}$ & $\begin{array}{r}8 \\
24 \\
48\end{array}$ & $\begin{array}{l}\text { Fluvoxamine superior to placebo in follow-up phase, } \\
\text { but only for depression }\end{array}$ \\
\hline Katz et al. (1990) & Clomipramine ${ }^{\mathrm{b}}$ & 110 & $(10+) 52$ & Superiority of clomipramine sustained in follow-up phase \\
\hline Tollefson et al. (1994) & Fluoxetine $^{\mathrm{b}}$ & 76 & $(13+) 24$ & Improvement on all doses, $60 \mathrm{mg}$ significant above others \\
\hline Greist et al. (1995a) & Sertraline $^{\mathrm{b}}$ & 118 & $(12+) 40$ & $\begin{array}{l}\text { Significant additional improvements in OCD symptoms } \\
\text { for sertraline }\end{array}$ \\
\hline
\end{tabular}

a Extended double-blind study.

${ }^{\mathrm{b}}$ Double-blind continuation in acute phase $(\times \mathrm{wk})$ responders.

responded in parallel with OCD, and shared its characteristic selectivity for the serotonergic drug. It is unusual for an antidepressant like desipramine to show such a poor response. These results suggest that the depression is either integral or secondary to OCD, and imply that depressed patients with OCD should be treated with an SRI. OCD frequently co-occurs with bipolar disorder, with lifetime comorbidity as high as 30\% (Kruger et al., 1995). This presents a challenge since SRIs can be associated with a switch to mania. SSRIs are less risky than clomipramine in this respect, and judicious administration of mood-stabilizing medication together with caution in dose escalation are advisable (Kaplan and Hollander, 2003). Unlike drugs, studies of behaviour therapy suggest that moderately high levels of baseline depression adversely affect the treatment outcome (Kejsers et al., 1994). This disadvantage may be neutralized by augmenting psychotherapy with a SSRI (Hohagen et al., 1998), although studies investigating this have been unable to disentangle the anti-obsessional effects of medication from those of behavioural interventions. These findings suggest that the first-line treatment for depressed patients with OCD should be a SSRI.

\section{Other treatments}

Preliminary reports hinting at benefits for a variety of agents acting on serotonin, such as mianserin and mirtazapine (Koran et al., 2001a), and the serotonin precursor L-tryptophan (Montgomery et al., 1992), are of theoretical value. There has been particular interest in the role of venlafaxine in OCD which, in low doses, acts mainly as a SSRI, but in doses exceeding $225 \mathrm{mg}$ combines this activity with norepinephrine reuptake inhibition. A small, placebo-controlled trial $(n=30)$ failed to separate venlafaxine from placebo
(Yaryura-Tobias and Neziroglu, 1994). Venlafaxine was also compared to paroxetine in a non-placebo, doubleblind study of non-depressed OCD cases (Denys et al., 2003a) where 75 individuals received paroxetine $(60 \mathrm{mg})$ and 75 venlafaxine $(300 \mathrm{mg})$. Both treatments appeared equally effective at reducing YBOCS scores. An evaluation of quality-of-life measures from the study also showed equivalent improvements (Tenney et al., 2003). A smaller single-blind study comparing venlafaxine with clomipramine also failed to reach significance, although $42.6 \%$ (20/47) of the clomipramine group were responders compared to $34.6 \%$ $(9 / 26)$ on venlafaxine on the ITT analysis (Albert et al., 2002). Further evaluation of the relative efficacy and tolerability of venlafaxine is warranted.

\section{How long should treatment be continued?}

OCD is a long-term illness and we need to know if acute treatments maintain efficacy in the longer term. In comparison to the evidence base for acute treatment of OCD, the long-term outcome is less clear. Evidence for long-term efficacy can be derived from a variety of sources. Some investigators have followed treatment responders from acute-phase studies on uncontrolled SRIs for up to $2 \mathrm{yr}$, without tolerance developing. The study by Wagner et al. (1999), reported ongoing efficacy for open-label sertraline up to $1 \mathrm{yr}$ in a large cohort of children and adolescents. Evidence from controlled studies is more convincing (Table 4). Cottraux et al. (1990) reported a significant benefit for fluvoxamine over placebo, but only for depressive symptoms. Katz et al. (1990) randomized patients to either clomipramine $(100-300 \mathrm{mg}$ ) or placebo for $10 \mathrm{wk}$, after which they entered 124 responders into a 52-wk double-blind extension period. Clomipramine's superiority over placebo was sustained over the 
extension phase, to the extent that OCD was no longer compromising the lives of half the clomipramine group. However, a high incidence of adverse effects in the clomipramine group resulted in $23 \%$ withdrawing early.

Tollefson et al. (1994) followed up 76 responders from the 13-wk multiple fixed-dose, placebo-controlled fluoxetine study on their ascribed treatment up to $24 \mathrm{wk}$. Patients on all doses of fluoxetine $(20,40$, $60 \mathrm{mg}$ ) continued to improve, with further significant improvements evident for the 60-mg group only. Only $6 \%$ of fluoxetine-treated individuals discontinued due to side-effects. In the large extension study by Greist et al. (1995a), 118 patients who had responded to 12 -wk treatment with sertraline or placebo continued under double-blind conditions for $40 \mathrm{wk}$. The patients maintained their improvements as long as they remained on sertraline. Compliance was good: only $13 \%$ patients dropped out of treatment prematurely during the extension phase. Of these, one third blamed side-effects and two thirds blamed unsatisfactory clinical response. Side-effects improved over time, and there were no statistically significant differences between sertraline and placebo in vital signs or laboratory abnormalities. Fifty-nine completers were followed up for a further year on open-label sertraline, and showed significant additional improvements in OCD symptoms over the course of the second year, with a reduced incidence of side-effects compared to the earlier study (Rasmussen et al., 1997).

\section{How long should treatment continue?}

One way of tackling this question is to explore whether continuation of pharmacotherapy provides ongoing protection against deterioration. A promising technique involves taking patients who have responded to active drug and comparing their 'relapse' rates following randomization to either continuous drug treatment or drug discontinuation. Planning and interpretation of drug-discontinuation studies is not always straightforward. There is still debate about the definition of a meaningful clinical response and the concept of 'relapse' has been even more difficult to apply to an illness that runs a chronic course and shows partial response to long-term treatment. Indeed, the lack of agreed definitions for 'relapse' makes inter-study comparison difficult. Criteria such as $\geqslant 50 \%$ worsening of post-baseline YBOCS improvement, 5-point worsening of YBOCS, YBOCS total score of $\geqslant 19$, CGI-I scores of 'much' or 'very much worse' have been proposed. Some studies have erred towards imposing too stringent qualifications, requiring more than two criteria to be present at any one time (Romano et al., 2001), or requiring criteria to persist over several visits (Koran et al., 2002). This has compromised the sensitivity to detect outcome differences. In addition, studies need to differentiate between early 'withdrawal effects' occurring soon after drug termination, and a more gradual reemergence of OCD. Withdrawal effects are related to the pharmacological properties of the compound, and are believed to complicate clomipramine and paroxetine more than fluoxetine (Rosenbaum et al., 1998).

A series of controlled studies has shown that discontinuation of treatment is positively associated with symptomatic relapse, irrespective of treatment duration (up to $2 \mathrm{yr}$ ) (Table 5). For most agents, symptoms re-emerged within only a few weeks of stopping medication. The earlier clomipramine studies showed relatively high, early relapse rates, possibly related to stronger withdrawal symptoms. For example, in the discontinuation study by Pato et al. (1988), 16 out of 18 patients exhibiting sustained improvements on clomipramine showed substantial worsening of symptoms within $4 \mathrm{wk}$ of crossing over to placebo. The re-emergence of symptoms was gradual and progressive and unrelated to duration of clomipramine pre-treatment, which exceeded $2 \mathrm{yr}$ in some cases. In this study, reinstatement of clomipramine resulted in improvement to a level close to pre-discontinuation, although other authors have reported less favourable results. Similarly, in the study by Leonard et al. (1988), 89\% patients relapsed within 2 months of switching to placebo.

In the relapse-prevention study by Romano et al. (2001), responders to 20-wk fixed-dose fluoxetine were randomized to continuation or placebo and followed up for a year. Relapses were stringently defined, and 38\% relapsed over 12 months following double-blind discontinuation. Patients remaining on the highest dose $(60 \mathrm{mg})$ showed significantly lower relapse rates $(17.5 \%)$, but the study still did not discriminate between continuation and switching. In spite of its larger size and longer duration, the study by Koran et al. (2002) was also unable to demonstrate a significant advantage for sertraline on the a-priori criterion for preventing relapse; in this case almost certainly because the criterion for relapse was too strictly defined. However, those remaining on sertraline showed significantly fewer 'drop-outs due to relapse or insufficient clinical response' (9\% vs. $24 \%$ on placebo) and 'acute exacerbation of symptoms' (12\% vs. $25 \%$ on placebo), and ongoing sertraline was associated with continued improvement in 
Table 5. Double-blind discontinuation studies of relapse prevention in OCD

\begin{tabular}{|c|c|c|c|c|c|}
\hline Study & Drug & $\begin{array}{l}\text { Duration } \\
\text { prior drug } \\
\text { treatment }\end{array}$ & $\begin{array}{l}\text { No. in } \\
\text { discontinuation } \\
\text { phase }\end{array}$ & $\begin{array}{l}\text { Follow-up after } \\
\text { discontinuation } \\
\text { (wk) }\end{array}$ & Outcome \\
\hline $\begin{array}{l}\text { Yaryura-Tobias et al. } \\
(1976)\end{array}$ & Clomipramine & 4 or $6 \mathrm{wk}$ & 13 & 1 & Worsening of OCD on placebo \\
\hline Flament et al. (1985) ${ }^{\mathrm{a}}$ & Clomipramine & $5 \mathrm{wk}$ & 19 & 5 & Worsening of OCD on placebo \\
\hline Pato et al. (1988) & Clomipramine & 5-27 months & 18 & 7 & $94.4 \%$ relapsed on placebo \\
\hline Leonard et al. $(1988)^{\mathrm{b}}$ & Clomipramine & 17 months & 21 & 5 & $89 \%$ relapsed on placebo \\
\hline Dunbar et al. (1995) ${ }^{c}$ & Paroxetine & 9 months & 104 & 36 & $\begin{array}{l}\text { Relapse rate on } \\
\text { placebo }>\text { paroxetine }\end{array}$ \\
\hline Romano et al. $(2001)^{c}$ & Fluoxetine & $20 \mathrm{wk}$ & 71 & 52 & $\begin{array}{l}\text { Relapse rate on placebo }= \\
\text { pooled fluoxetine } \\
\text { Relapse rate on } \\
\text { placebo }>\text { fluoxetine } 60 \mathrm{mg}\end{array}$ \\
\hline Koran et al. (2002) ${ }^{c}$ & Sertraline & $52 \mathrm{wk}$ & 223 & 28 & $\begin{array}{l}\text { Relapse rate on } \\
\text { placebo }=\text { sertraline } \\
\text { Acute exacerbation of OCD on } \\
\text { placebo }>\text { sertraline } \\
\text { Drop-outs due to relapse on } \\
\text { placebo }>\text { sertraline }\end{array}$ \\
\hline Geller et al. $(2003 b)^{b}$ & Paroxetine & $16 \mathrm{wk}$ & 193 & 16 & $\begin{array}{l}\text { Relapse rate on placebo }= \\
\text { paroxetine }\end{array}$ \\
\hline Hollander et al. $(2003 b)^{c}$ & Paroxetine & $12 \mathrm{wk}$ & 105 & 36 & $\begin{array}{l}\text { Relapse rate on placebo }> \\
\text { paroxetine }\end{array}$ \\
\hline
\end{tabular}

a In children.

${ }^{\mathrm{b}}$ In children and adolescents.

c Survival analysis performed.

YBOCS, NIMH-OC, CGI scores and quality-of-life measures.

A discontinuation study investigating adults who had responded to 6 months' paroxetine (Dunbar et al., 1995) was presented at an international meeting but has not been published. Results showed that those who continued on paroxetine suffered significantly fewer relapses during the next $36 \mathrm{wk}$ than those who switched to placebo. Approximately $10 \%$ of paroxetine-treated patients had a full relapse, compared to $18 \%$ on placebo. The ITT analysis showed a significantly shorter time-to-relapse on placebo. YBOCS scores were maintained or slightly improved under paroxetine, but deteriorated under placebo. A more recent large-scale study of paroxetine by Hollander et al. (2003b) looked at 105 responders to 6 months' treatment and demonstrated a significantly better outcome for those remaining on the active drug over the 6-month, double-blind discontinuation phase: $59 \%$ of patients randomized to placebo relapsed, compared to $38 \%$ on paroxetine (20-60 mg), with paroxetine being well tolerated across the dose range. Geller et al. (2003b) investigated paroxetine in children and adolescents, of whom more than half had at least one comorbid illness, using a relapse-prevention design. After 16-wk open-label paroxetine, 193 responders were randomized to a further 16-wk double-blind treatment on paroxetine or placebo. The overall relapse rate was not significantly higher in the placebo than the paroxetine group $(43.9 \%$ vs. $34.7 \%)$, possibly because the duration of follow-up was too short. Post-hoc analyses showed a significantly greater relapse rate for patients with comorbid disorders than those with uncomplicated OCD randomized to placebo, but this did not apply under paroxetine. The authors argued that patients with comorbidity are at increased risk of relapse following discontinuation and that studies which too rigorously exclude comorbid disorders may underestimate relapse rates in clinical samples of OCD.

It is difficult to draw strong conclusions from these mixed findings. We may surmise that medication probably confers protection against relapse, as long as it is continued. The Expert Consensus Guidelines (March et al., 1997) recommended pharmacotherapy maintenance for a minimum of 3-6 months after 
acute treatment, reserving long-term treatment only for subsequent relapses. However, it was also noted that much longer periods, exceeding $2 \mathrm{yr}$, were usually needed, and that lifelong treatment was warranted after $2-4$ relapses. More recent guidelines (Greist et al., 2003) have more strongly emphasized the importance of long-term treatment from the outset and recommended continuation of pharmacotherapy for a minimum of $1-2 \mathrm{yr}$ in treatmentresponsive individuals. Discontinuation, if necessary, should be gradual to minimize discontinuation effects, and patients should be warned to look out for early signs of relapse whereupon reinstatement of pharmacotherapy may achieve the same level of improvement as before, although this cannot be guaranteed (Ravizza et al., 1998). Until clear predictors relating to relapse are available, lifelong medication may be the best option for most cases.

\section{What is the best dose for long-term treatment?}

There is little evidence supporting dose reduction in long-term treatment, apart from one small study where lowering the dose of clomipramine and fluvoxamine did not affect relapse rates (Mundo et al., 1997b). Results from Romano et al.'s (2001) study, in which a 60-mg dose of fluoxetine appeared the most effective over the 24-wk extension phase, support continuation of treatment at higher dose levels. On the basis of the limited data available, most experts recommend continuing treatment at the effective dose, and the adage 'the dose that gets you well, keeps you well' probably applies.

\section{Preferred treatments after poor response to first-line drugs}

\section{Predictors of treatment response}

Although most patients experience substantial improvements, for many the treatment response is not complete. In approx. $30 \%$ cases residual symptoms remain in spite of prolonged treatment with SRIs. The problem of 'partial responders' is an area that has received inadequate controlled investigation and which is bedevilled by the lack of universally accepted definitions. Pallanti et al. (2002a) advocated the use of standardized operational criteria across treatment trials. Specifically, they proposed that an improvement of $\geqslant 35 \%$ in baseline YBOCS score, or 'much' or 'very much improved' on the CGI-I, represented a meaningful clinical response, while 'remission' required a total YBOCS score of $<16$. Those showing between $25 \%$ and $35 \%$ improvement in YBOCS scores were considered partial responders. Relapse was defined as a $25 \%$ worsening in YBOCS (or a CGI score of 6), after a period of remission, and the term 'treatment refractory' was reserved for those who do not respond to 'all available treatments'. Levels of nonresponse, according to the numbers of failed treatments, were also defined.

Few studies provide information on response status, and the literature on pharmacological response predictors is sparse and inconsistent. Mataix-Cols et al.'s (1999) factor analysis suggests that adults with compulsive rituals, early-onset age, longer duration, chronic course, comorbid tics and personality disorders (especially schizotypal), respond poorly to clomipramine and SSRIs. Additional analyses of large databases for clomipramine and fluoxetine reported better responses for previously SRI-naive patients, and poorer responses for those with subclinical depression. Patients with an earlier age of onset responded poorly to clomipramine, but not to fluoxetine (Ackerman and Greenland, 2002). The more recent analysis of data from a large trial of citalopram also reported that patients with a longer duration of illness or previous SSRI treatment, as well as greater illness severity, were less likely to respond well to the active drug (Stein et al., 2001). One small study has identified better responses in females (Mundo et al., 1999) and children with comorbid ADHD, tic disorder and oppositional defiant disorder showed a less favourable response (Geller et al., 2003b).

\section{Switching SRI, increasing dose or changing mode of drug delivery}

Given the limitations of data supporting alternative strategies, and the acceptability of switching from one SSRI to another, this remains the preferred option for many clinicians. Sometimes, however, it may be appropriate to persist for longer with a particular SRI even in patients who show little sign of improvement, since a delayed response may occur after 6 months or more. March et al. (1997) recommended changing the SRI after $8-12 \mathrm{wk}$ on the maximal dose if the clinical effect was incomplete. They proposed a $40 \%$ chance of responding to a second SRI, and a lesser response to a third and suggested switching to clomipramine after 2-3 failed trials on SSRIs. An unpublished report by Ravizza et al. (2001) looked at patients who had failed to respond to at least two trials of SSRIs other than citalopram. Patients were randomized to clomipramine, venlafaxine or citalopram for $12 \mathrm{wk}$ and $14 \%$ responded to citalopram, $37.5 \%$ to clomipramine and $42 \%$ to venlafaxine. A single-blind study 
in 29 cases of SRI-resistant OCD showed encouraging results for venlafaxine $(37.5-375 \mathrm{mg}$ ) as a monotherapy (Hollander et al., 2003c). These results hint that patients who have failed to respond to two SSRIs may benefit from switching to an agent with a different mode of action.

Results from uncontrolled case studies suggest that, for some patients, increasing SSRI doses above formulary limits can procure a better effect (Bejerot and Bodland, 1998; Byerly et al., 1996). Although doses of clomipramine up to $300 \mathrm{mg}$ have been systematically investigated and found to be acceptable, the risk of seizures and cardiotoxicity associated with this drug suggest that doses exceeding this should be generally avoided. Altering the mode of administration may be considered although this is not practical in many cases. Intravenous clomipramine has been shown to be more effective than placebo in a single, double-blind study investigating refractory OCD, with 6 out of 29 randomized to clomipramine classed as responders after 14 daily infusions, compared to none for placebo (Fallon et al., 1998). A positive open study of 21-d intravenous citalopram has also been reported (Pallanti et al., 2002b).

\section{Combining SRIs and drugs exerting antidepressant or anxiolytic properties}

If a patient fails to respond to successive SRI trials, augmented with CBT, the Expert Consensus Guideline recommends adding another agent to the SRI. The evidence is acknowledged to be limited, based on the results of small studies and open case-series (Table 6). Combining clomipramine with a SSRI has been proposed for adults or children unresponsive to, or intolerant of, SRI monotherapy. This strategy should be approached with caution since the pharmacokinetic interactions on the hepatic cytochrome P450 isoenzymes may lead to a build-up of clomipramine that could be dangerous, and ECG and plasma-level monitoring is advisable. Positive results have been reported from small, uncontrolled case series (Szegedi et al., 1996), although the fluoxetine-clomipramine combination resulted in ECG changes in some cases. Pallanti et al. (1999) compared nine treatment-refractory patients given citalopram + clomipramine with seven given citalopram alone, in a randomized openlabel trial. They reported a significantly larger improvement in YBOCS ratings for those given the combination, all of whom experienced decreases $\geqslant 35 \%$ from baseline. This combination is advantageous in not altering the metabolism of clomipramine, and was well tolerated. No controlled studies
Table 6. Treatment refractory OCD

Double-blind, placebo-controlled pharmacotherapy studies

May be effective

- Intravenous clomipramine ${ }^{\mathrm{a}}$

- Adding haloperidol ${ }^{\mathrm{C}}$

- Adding risperidone

- Adding quetiapine

- Adding clonazepam ${ }^{\mathrm{b}}$

Apparently ineffective

- Adding lithium

- Adding buspirone

- Adding triiodothyronine (liothyronine)

- Adding desipramine

- Adding inositol

Promising treatments warranting controlled study

- Higher-dose SSRI monotherapy

- Combined SSRI-clomipramine treatment

- Extended SRI therapy

- Adding olanzapine

- Adding amisulpride

- Intravenous citalopram

- Tryptans that enter the CNS, e.g. zolmitriptan

- Immunoglobulins and plasmapharesis

- Deep brain stimulation

- Neurosurgery (gamma knife surgery)

${ }^{\text {a }}$ Remains investigational in many countries.

${ }^{\mathrm{b}}$ Small numbers and improvement not evident on all OCD rating scales.

' Primarily in 'tic-related' OCD.

of the co-administration of different SSRIs have been published.

Controlled studies have confirmed the lack of efficacy of lithium augmentation in OCD (McDougle et al., 1991; Pigott et al., 1991). Similarly, three doubleblind, placebo-controlled studies have demonstrated that combining buspirone with an SRI is not helpful (Grady et al., 1993; McDougle et al., 1993; Pigott et al., 1992a). Clonazepam is a benzodiazepine with putative effects on serotonin neurotransmission. As a monotherapy it fails to impact on the core symptoms of OCD (Hollander et al., 2003d) although it may help with associated anxiety. Pigott et al. (1992b) reported limited efficacy for clonazepam given together with fluoxetine or clomipramine in a placebocontrolled study. Pindolol is a beta-blocker which also acts as an antagonist at pre-synaptic 5-HT1A autoreceptors. Dannon et al. (2000) demonstrated efficacy for pindolol when combined with paroxetine in a double-blind, placebo-controlled study of 14 treatment-resistant cases, but another study combining it 
with fluvoxamine did not (Mundo et al., 1998). Blier and Bergeron (1996) found a beneficial effect for pindolol only when L-tryptophan was openly added to the combination. The limitations of adding drugs acting on serotonin led investigators to re-examine the role of noradrenergic agents in resistant OCD. Barr et al. (1997) investigated the addition of desipramine to 20 patients who had failed SSRI monotherapy, in a double-blind, placebo-controlled study, and found no added benefit.

\section{Combining SRIs and drugs with antipsychotic properties}

No positive studies of antipsychotic monotherapy in OCD meet today's standards, and OCD is not recognized as responding to these drugs individually. McDougle et al. (1990) reported a benefit from adding open-label pimozide $(6.5 \mathrm{mg})$ in 17 patients unresponsive to fluvoxamine. Patients with comorbid chronic tics or schizotypal disorder were most responsive. A subsequent double-blind, placebo-controlled study by the same author demonstrated a significant YBOCS improvement for low-dose haloperidol $(6.2 \mathrm{mg})$ added to fluvoxamine. Eleven out of 17 patients receiving the active drug achieved 'responder' status by as early as $4 \mathrm{wk}$, compared to none on placebo. Again, a preferential response was seen in patients with comorbid tics (McDougle et al., 1994). Antipsychotics such as haloperidol and sulpiride are first-line treatments for Tourette's syndrome, so this finding supports a theoretical link between these disorders. This combination increases the side-effect burden, including extra-pyramidal effects. It is therefore wise to start treatment with very low doses, and increase cautiously subject to tolerability (e.g. $0.25-0.5 \mathrm{mg}$ haloperidol, titrated slowly to $2-4 \mathrm{mg}$; McDougle and Walsh, 2001).

Newer second-generation antipsychotics, that modulate serotonin and dopamine neurotransmission, also offer promise and have a lower risk for sideeffects. Positive reports from open case-series were confirmed by McDougle et al. (2000) in the first reported double-blind, placebo-controlled study showing efficacy for risperidone augmentation in 36 patients unresponsive to $12 \mathrm{wk}$ on an SRI. Risperidone $(2.2 \mathrm{mg})$ was superior to placebo in reducing YBOCS scores as well as anxiety and depression, was well tolerated and there was no difference between those with and without comorbid tics or schizotypy. A smaller double-blind study by Hollander et al. (2003e) examined patients failing to respond to at least two trials of SRIs. Four out of 16 patients randomized to risperidone $(0.5-3 \mathrm{mg})$ turned out to be responders, defined as a CGI-I score of 1 or 2 and a YBOCS decrease of $\geqslant 25 \%$ at the 8 -wk end-point, compared to none of the six patients randomized to placebo.

Quetiapine has also been the subject of recent controlled investigation. There have been contradictory results from open (Sevincok and Topuz, 2003) and single-blind studies (Atmaca et al., 2002). However, the recent double-blind, placebo controlled study by Denys et al. (2003b), published in abstract form, showed clear evidence of efficacy for 8-wk quetiapine (<300 mg) augmentation in 20 SRI-refractory patients, showing a mean decrease of $30 \%$ on baseline YBOCS, compared to 20 controls who showed only $6 \%$ improvement. Encouraging results from a small number of open-label studies of olanzapine (D'Amico et al., 2003) and an open-label study of amisulpride (Metin et al., 2003) suggest that these drugs may also be helpful, and further investigation is underway. The results for clozapine have been less encouraging (McDougle et al., 1995). Some authors report emergent obsessions during treatment with atypical antipsychotics, which may be related to their mixed receptor antagonist properties. Altogether, these results favour the use of second-generation antipsychotics as the first-line strategy for augmentation in resistant OCD. It remains uncertain as to how long patients need to remain on augmented treatment. A small retrospective study by Maina et al. (2003b) showed that the vast majority of patients who had responded to the addition of an antipsychotic to their SRI, subsequently relapsed when the antipsychotic was withdrawn.

\section{Other strategies for refractory OCD}

Inositol $(18 \mathrm{~g} / \mathrm{d})$ is an experimental compound that acts through intracellular messenger systems. It was thought to have mild anti-obsessional efficacy but results from a placebo-controlled augmentation study by Fux et al. (1999) refute this. Sumatriptan is a 5HT1D agonist used to treat migraine. A small open case-series suggested improvement over 4-wk treatment but, in a double-blind, placebo-controlled study of 10 patients, 5-d treatment was associated with a worsening of OCD (Koran et al., 2001b). Drugs that alter immune system response may have a role in refractory OCD. For example, syndromes of sudden-onset OCD following childhood streptococcal infections are recognized, and these may respond to plasmapharesis and intravenous immunoglobulin (Perlmutter et al., 1999). Preliminary reports that repetitive trans-cranial magnetic stimulation may 
reduce compulsions (Greenberg et al., 1997) have not been substantiated in treatment studies. Neither is ECT considered effective, although it may help relieve severe comorbid depression. Stereotactic neurosurgery should be viewed as a last option. Techniques such as cingulotomy and capsulotomy have produced improvements in some intransigent cases, but the absence of controlled trial data, including long-term follow-up on adverse effects, is discouraging. Deep brain stimulation involves less intra-cerebral neuronal damage and holds promise for future investigation.

\section{Conclusions}

An extensive evidence base now exists for the pharmacological management of OCD. First-line treatment with a SSRI is uncontroversial, with improvements being sustained over time, although response is often incomplete with many individuals failing to respond adequately. Treatment-resistant OCD is now receiving systematic evaluation: augmentation with secondgeneration antipsychotic agents appears a promising strategy and other techniques for resistant cases are under evaluation. Important questions requiring further investigation include identification of clinically relevant predictors relating to treatment-response and relapse, the clarification of optimal duration of treatment and the evaluation of anti-obsessional treatment in comorbid disorders such as schizophrenia with OCD. Agreed definitions for response, relapse, resistance and refractoriness will improve research in this area.

\section{Acknowledgements}

The authors thank Joan Lomas and Jill Jones, from the QEII Hospital Library for help in obtaining manuscripts, and Kerry Foley and Penny Davy for assistance with reference formatting. Finally we are grateful to Professor B. Lerer and three anonymous reviewers for their insightful comments on an earlier draft.

\section{Statement of Interest}

Naomi Fineberg has participated in several trials in OCD sponsored by the pharmaceutical industry, and has received honoraria for lectures and remuneration for consultation work, and sponsorship to attend scientific congresses. Companies include: Lundbeck (consultation, sponsorship for trials, lectures and congresses), AstraZeneca (sponsorship for trials and attendance at congresses), Solvay (support for attendance at congresses), Lilley (sponsorship for trials and attendance at meetings), Novartis (sponsorship for attendance at congresses), Roche (trial sponsorship), Pfizer (sponsorship for lectures and attendance at conferences), Janssen (sponsorship for attendance at congresses). Tim Gale is participating in a trial sponsored by Lundbeck.

\section{References}

Abramowitz JS (1997). Effectiveness of psychological and pharmacological treatments for obsessive compulsive disorder: a quantitative review. Journal of Consulting and Clinical Psychology 65, 44-52.

Ackerman DL, Greenland S (2002). Multivariate metaanalysis of controlled drug studies for obsessive compulsive disorder. Journal of Clinical Psychopharmacology 22, 309-317.

Aizenberg D, Naor S, Zemishlany Z, Weizman A (1999). The serotonin antagonist mianserin for treatment of serotonin-reuptake inhibitor-induced sexual dysfunction: an open-label study. Clinical Neuropharmacology 22, 347-350.

Albert U, Aguglia E, Maina G, Bogetto F (2002). Venlafaxine versus clomipramine in the treatment of obsessive compulsive disorder: a preliminary, single-blind 12-week controlled study. Journal of Clinical Psychiatry 63, 1004-1009.

Ananth J, Pecknold JC, Van Den Steen N, Engelsmann F (1981). Double-blind comparative study of clomipramine and amitriptyline in obsessional neurosis. Progress in Neuro-Psychopharmacology 5, 257-262.

Asberg M, Montgomery SA, Perris C, Schalling D, Sedvall G (1978). A comprehensive psychopathological rating scale. Acta Psychiatrica Scandinavica (Suppl.) 271, 5-27.

Atmaca M, Kuloglu M, Tezcan E, Gecici O (2002). Quetiapine augmentation in patients with treatmentresistant obsessive compulsive disorder. A single blind, placebo-controlled study. International Clinical Psychopharmacology 17, 115-119.

Barr LC, Goodman WK, Anand A, McDougle CJ, Price LH (1997). Addition of desipramine to serotonin reuptake inhibitors in treatment-resistant obsessive-compulsive disorder. American Journal of Psychiatry 154, 1293-1295.

Beasley CM, Potvin JH, Masica DN, Wheadon DE, Dornseif BE, Genduso LA (1992). Fluoxetine: no association with suicidality in obsessive-compulsive disorder. Journal of Affective Disorders 24, 1-10.

Bejerot S, Bodlund O (1998). Response to high doses of citalopram in treatment-resistant obsessive compulsive disorder. Acta Psychopharmacologica Scandinavia 98, 423-424.

Bergeron R, Ravindran AV, Chaput Y, Golder E, Swinson R, van Amerigen MA, Austin C, Hadrava V (2001). Sertraline and fluoxetine treatment of obsessive compulsive disorder: results of a double-blind, 6-month treatment study. Journal of Clinical Psychopharmacology 22, 148-154. 
Bisserbe JC, Lane RM, Flament MF (1997). A double-blind comparison of sertraline and clomipramine in outpatients with obsessive-compulsive disorder. European Psychiatry 12, 82-93.

Blier P, Bergeron R (1996). Sequential administration of augmentation strategies in treatment resistant obsessive compulsive disorder: preliminary findings. International Clinical Psychopharmacology 11, 37-44.

Bogetto F, Albert U, Maina G (2002). Sertraline treatment of obsessive-compulsive disorder: efficacy and tolerability of a rapid titration regimen. European Neuropsychopharmacology 12, 181-186.

Byerly MJ, Goodman WK, Christenen R (1996). High doses of sertraline for treatment-resistant obsessive compulsive disorder. American Journal of Psychiatry 153, 1232-1233.

Chouinard G, Goodman W, Greist J, Jenike M, Rasmussen S, White K, Hackett E, Gaffney M, Bick PA (1990). Results of a double-blind placebo-controlled trial of a new serotonin reuptake inhibitor, sertraline, in the treatment of obsessive-compulsive disorder. Psychopharmacology Bulletin 26, 279-284.

Clomipramine Collaborative Study Group (1991). Clomipramine in the treatment of patients with obsessive compulsive disorder. Archives of General Psychiatry 48, 730-738.

Cottraux J, Mollard E, Bouvard M, Marks I, Sluys M, Nury AM, Douge R, Cialdella P (1990). A controlled study of fluvoxamine and exposure in obsessive-compulsive disorder. International Clinical Psychopharmacology 5, 17-30.

D'Amico G, Cedro C, Muscatello MR, Pandolfo G, Di Rosa AE, Zoccali R, La Torre D, D'Amigo C, Spina E (2003). Olanzapine augmentation of paroxetine-refractory obsessive-compulsive disorder. Progress in Neuropsychopharmacology and Biological Psychiatry 27, 619-623.

Dannon PN, Sasson Y, Hirschmann S, Iancu I, Grunhaus LJ, Zohar J (2000). Pindolol augmentation in treatmentresistant obsessive compulsive disorder. A double-blind placebo-controlled trial. European Neuropsychopharmacology 10, 165-169.

Denys D, De Geus F, Van Megen HJ, Salzman C, Westenberg HG (2003b). A double-blind placebocontrolled trial of quetiapine augmentation in patients with obsessive compulsive disorder resistant to serotonin reuptake inhibitors. European Neuropsychopharmacology 13 (Suppl.), S361.

Denys D, van der Wee N, van Megen HJ, Westenberg HG (2003a). A double blind comparison of venlafaxine and paroxetine in obsessive-compulsive disorder. Journal of Clinical Psychopharmacology 23, 568-575.

De Veaugh-Geiss J, Landau P, Katz R (1989). Treatment of obsessive compulsive disorder with clomipramine. Psychiatric Annals 19, 97-101.

De Veaugh-Geiss J, Moroz G, Biederman J, Cantwell D, Fontaine R, Greist JH, Reichler R, Katz R, Landau P (1992). Clomipramine hydrochloride in childhood and adolescent obsessive compulsive disorder: a multicenter trial. Journal of the American Academy of Child and Adolescent Psychiatry 31, 45-49.
Dunbar G, Steiner M, Bushnell WD, Gergel I, Wheadon DE (1995). Long-term treatment and prevention of relapse of obsessive compulsive disorder with paroxetine. European Neuropsychopharmacology 5, 372 (P-D-11).

Fallon BA, Liebowitz MR, Campeas R, Schneier FR, Marshall R, Davies S, Goetz D, Klein DF (1998). Intravenous clomipramine for obsessive-compulsive disorder refractory to oral clomipramine: a placebocontrolled study. Archives of General Psychiatry 55, 918-924.

Fernandez CE, Lopez-Ibor JJ (1967). Monochlorimipramine in the treatment of psychiatric patients resistant to other therapies. Actas Luso-Españolas de Neurología Psíquiatría y Ciencias Afines 26, 119-147.

Fineberg NA, Roberts A, Montgomery SA, Cowen PH (1997). Brain 5-HT function in obsessive-compulsive disorder: prolactin responses to d-fenfluramine. British Journal of Psychiatry 171, 280-282.

Flament MF, Rapoport JL, Berg CJ, Sceery W, Kilts C, Mellstrom B, Linnoila M (1985). Clomipramine treatment of childhood obsessive-compulsive disorder. A double-blind controlled study. Archives of General Psychiatry 42, 977-983.

Foa EB, Steketee G, Kozak MJ, Dugger D (1987). Imipramine and placebo in the treatment of obsessive-compulsives: their effect on depression and obsessional symptoms. Psychopharmacology Bulletin 23, 8-11.

Freeman CPC, Trimble MR, Deakin JFW, Stokes TM, Ashford JJ (1994). Fluvoxamine versus clomipramine in the treatment of obsessive-compulsive disorder: a multicenter, randomized, double-blind parallel group comparison. Journal of Clinical Psychiatry 55, 301-305.

Fux M, Benjamin J, Belmaker RH (1999). Inositol versus placebo augmentation of serotonin reuptake inhibitors in the treatment of obsessive-compulsive disorder: a double-blind cross-over study. International Journal of Neuropsychopharmacology 2, 193-195.

Geller DA, Biederman J, Stewart SE, Mullin A, Spencer T, Faraone SV (2003a). Which SSRI? A meta-analysis of pharmacotherapy trials in paediatric obsessivecompulsive disorder. American Journal of Psychiatry 160, 1919-1928.

Geller DA, Biederman J, Stewart SE, Mullin B, Farrell C, Wagner KD, Emslie G, Carpenter D (2003b). Impact of comorbidity on treatment response to paroxetine in paediatric obsessive compulsive disorder: is the use of exclusion criteria empirically supported in randomised controlled trials? Journal of Child and Adolescent Psychopharmacology 13 (Suppl.), S19-29.

Geller DA, Hoog SL, Heiligenstein JH, Ricardi RK, Tamura R, Klussynski S, Jacobson JG, Fluoxetine Paediatric OCD Study Team (2001). Fluoxetine treatment for obsessive-compulsive disorder in children and adolescents: a placebo-controlled clinical trial. Journal of the American Academy of Child and Adolescent Psychiatry 40, 773-779.

Goodman WK, Kozak MJ, Liebowitz M, White KL (1996). Treatment of obsessive-compulsive disorder with Fluvoxamine: a multicentre, double-blind, 
placebo-controlled trial. International Clinical Psychopharmacology 11, 21-29.

Goodman WK, Price LH, Delgado PL, Palumbo J, Krystal JH, Nagy LM, Rasmussen SA, Heninger GR, Charney DS (1990). Specificity of serotonin reuptake inhibitors in the treatment of obsessive-compulsive disorder: comparison of fluvoxamine and desipramine. Archives of General Psychiatry 47, 577-585.

Goodman WK, Price LH, Rasmussen SA, Delgado PL, Heninger GR, Charney DS (1989). Efficacy of fluvoxamine in obsessive-compulsive disorder. A double-blind comparison with placebo. Archives of General Psychiatry $46,36-44$.

Goodman WK, Price LH, Rasmussen SA, Mazure C, Fleischmann RL, Gill CL, Heninger GR, Charney DS (1984). The Yale-Brown Obsessive Compulsive Scale: development, use and reliability. Archives of General Psychiatry 46, 1006-1011.

Grady TA, Pigott TA, L'Heureux F, Hill JL, Berntein SE, Murphy DL (1993). Double-blind study of adjuvant buspirone for fluoxetine-treated patients with obsessivecompulsive disorder. American Journal of Psychiatry 150, 819-821.

Greenberg BD, George MS, Martin DJ, Benjamin J, Schlaepfer TE, Altemus M, Wassermann EM, Post RM, Murphy DL (1997). Effect of prefrontal repetitive transcranial magnetic stimulation in obsessive-compulsive disorder: a preliminary study. American Journal of Psychiatry 154, 867-869.

Greist J, Chouinard G, DuBoff E, Halaris A, Kim SW, Koran L, Liebowitz M, Lydiard RB, Rasmussen S, White K, Sikes C (1995b). Double-blind parallel comparison of three dosages of sertraline and placebo in outpatients with obsessive-compulsive disorder. Archives of General Psychiatry 52, 289-295.

Greist JH, Bandelow B, Hollander E, Marazzitti D, Montgomery SA, Nutt DJ, Okasha A, Swinson RP, Zohar J (2003). Long-term treatment of obsessivecompulsive disorder in adults. CNS Spectrums $8,7-16$.

Greist JH, Jefferson JW, Kobak KA, Chouinard G, DuBoff E, Halaris A, Kim SW, Koran L, Liebowtiz MR, Lydiard B, McElroy S, Mendels J, Rasmussen S, White K, Flicker C (1995a). A one year double-blind placebo-controlled fixed dose study of sertraline in the treatment of obsessivecompulsive disorder. International Clinical Psychopharmacology 10, 57-65.

Greist JH, Jefferson JW, Kobak KA, Katzelnick DJ, Serlin RC (1995c). Efficacy and tolerability of serotonin transport inhibitors in obsessive-compulsive disorder: a meta-analysis. Archives of General Psychiatry 52, 53-60.

Greist JH, Jefferson JW, Rosenfeld R, Gutzmann LD, March JS, Barklage NE (1990). Clomipramine and obsessive compulsive disorder: a placebo-controlled double-blind study of 32 patients. Journal of Clinical Psychiatry 51, 292-297.

Hamilton M (1960). A rating scale for depression. Journal of Neurology, Neurosurgery and Psychiatry 23, 56-62.
Hodgson RJ, Rachman S (1977). Obsessional-compulsive complaints. Behavior Research and Therapy 15, 389-395.

Hoehn-Saric R, Ninan P, Black DW, Stahl S, Greist JH, Lydiard B, McElroy S, Zajecka J, Chapman D, Cary C, Harrison W (2000). Multicentre double-blind comparison of sertraline and desipramine for concurrent obsessivecompulsive and major depressive disorders. Archives of General Psychiatry 57, 76-82.

Hohagen F, Winkelmann G, Rasche-Ruchle H, Hand I, Kopnig A, Munchau N, Hiss H, Greiger-Kabisch C, Kappler C, Schramm P, Rey E, Aldenhoff J, Berger M (1998). Combination of behaviour therapy with fluvoxamine in comparison with behaviour therapy and placebo: results of a multicentre study. British Journal of Psychiatry 173, 71-78.

Hollander E, Allen A, Steiner M, Wheadon DE, Oakes R, Burnham DB (2003b). Acute and long-term treatment and prevention of relapse of obsessive-compulsive disorder with paroxetine. Journal of Clinical Psychiatry 64, 1113-1121.

Hollander E, Friedberg J, Wasserman S, Allen A, Birnbaum M, Koran LM (2003c). Venlafaxine in treatment-resistant obsessive-compulsive disorder. Journal of Clinical Psychiatry 64, 546-550.

Hollander E, Greenwald S, Neville D (1998). Uncomplicated and comorbid obsessive-compulsive disorder in an epidemiological sample. CNS Spectrums 3, 10-18.

Hollander E, Kaplan A, Stahl SM (2003d). A double-blind placebo-controlled trial of clonazepam in obsessivecompulsive disorder. World Journal of Biological Psychiatry 4, 30-34.

Hollander E, Koran LM, Goodman WK, Greist JH, Ninan PT, Yang H, Li D, Barbato LM (2003a). A doubleblind placebo-controlled study of the efficacy and safety of controlled release fluvoxamine in patients with obsessive-compulsive disorder. Journal of Clinical Psychiatry 64, 640-647.

Hollander E, Rossi NB, Sood E, Pallanti S (2003e). Risperidone augmentation in treatment-resistant obsessive compulsive disorder: a double-blind, placebo controlled study. International Journal of Neuropsychopharmacology 6, 397-401.

Hollander E, Wong C (1998). Psychosocial function and economic costs of obsessive compulsive disorder. CNS Spectrums 3 (5, Suppl. 1), 48-58.

Insel TR, Mueller EA, Alterman I, Linnoila M, Murphy DL (1985). Obsessive-compulsive disorder and serotonin: is there a connection? Biological Psychiatry 20, 1174-1188.

Insel TR, Murphy DL, Cohen RM, Alterman I, Kilts C, Linnoila M (1983). Obsessive-compulsive disorder - a double-blind trial of clomipramine and clorgyline. Archives of General Pychiatry 40, 605-612.

Jenike MA, Baer L, Minichiello WE, Raunch SL, Buttolph ML (1997). Placebo-controlled trial of fluoxetine and phenelzine for obsessive-compulsive disorder. American Journal of Psychiatry 154, 1261-1264.

Jenike MA, Baer L, Summergrad P, Minichiello WE, Holland A, Seymour R (1990b). Sertraline in 
obsessive-compulsive disorder: a double-blind comparison with placebo. American Journal of Psychiatry 147, 923-928.

Jenike MA, Baer L, Summergrad P, Weilburg JB, Holland A, Seymour R (1989). Obsessive-compulsive disorder: a double-blind, placebo-controlled trial of clomipramine in 27 patients. American Journal of Psychiatry 146, 1328-1330.

Jenike MA, Hyman S, Baer L, Holland A, Minichiello WE, Buttolph L, Summergrad P, Seymour R, Ricciardi J (1990a). A controlled trial of fluvoxamine in obsessivecompulsive disorder; implications for a serotonergic theory. American Journal Psychiatry 147, 1209-1215.

Kaplan A, Hollander E (2003). A review of pharmacologic treatments for obsessive-compulsive disorder. Psychiatric Services 54, 1111-1118.

Katz RJ, DeVeaugh-Geiss J, Landau P (1990). Clomipramine in obsessive-compulsive disorder. Biological Psychiatry 28, 401-404.

Kejsers G, Hoogdiun C, Schaap CP (1994). Predictors of treatment outcome in the behavioural treatment of obsessive-compulsive disorder. British Journal of Psychiatry 165, 781-786.

Kobak KA, Greist JH, Jefferson JW, Katzelnick DJ, Henk HJ (1998). Behavioural versus pharmacological treatments of obsessive compulsive disorder: a meta-analysis. Psychopharmacology 136, 205-216.

Koran LM, Hackett E, Rubin A, Wolkow R, Robinson D (2002). Efficacy of sertraline in the long-term treatment of obsessive-compulsive disorder. American Journal of Psychiatry 159, 89-95.

Koran LM, McElroy SL, Davidson JR, Rasmussen SA, Hollander E, Jenike MA (1996). Fluvoxamine versus clomipramine for obsessive-compulsive disorder: a double-blind comparison. Journal of Clinical Psychopharmacology 16, 121-129.

Koran LM, Pallanti S, Querciolil L (2001b). Sumatriptan, 5-HT(1D) receptors and obsessive compulsive disorder. European Neuropsychopharmacology 11, 169-172.

Koran LM, Quirk T, Lorberbaum JP, Elliott M (2001a). Mirtazepine treatment of obsessive-compulsive disorder. Journal of Clinical Psychopharmacology 21, 537-539.

Koran LM, Sallee FR, Pallanti S (1997). Rapid benefit of intravenous pulse-loading of clomipramine in obsessive compulsive disorder. American Journal of Psychiatry 154, 396-401.

Kronig MH, Apter J, Asnis G, Bystritsky A, Curtis G, Ferguson J, Landbloom R, Munjack D, Riesenberg R, Robinson D, Roy-Byrne P, Phillips K, Du Pont IJ (1999). Placebo-controlled, multicenter study of sertraline treatment for obsessive-compulsive disorder. Journal of Clinical Psychopharmacology 19, 172-176.

Kruger S, Cooke RG, Hasey GM, Jorna T, Persad E (1995). Comorbidity of obsessive compulsive disorder in bipolar disorder. Journal of Affective Disorders 34, 117-120.

Leibowitz MR, Turner SM, Piacentini J, Beidel DC, Clarvit SR, Davies SO, Graae F, Jaffer M, Lin SH, Sallee FR, Schmidt AB, Simpson HB (2002). Fluoxetine in children and adolescents with OCD: a placebo-controlled trial.
Journal of the American Academy of Child and Adolescent Psychiatry 41, 1431-1438.

Leonard HL, Swedo S, Rapoport JL, Coffey M, Cheslow D (1988). Treatment of childhood obsessive compulsive disorder with clomipramine and desmethylimipramine: a double-blind crossover comparison. Psychopharmacology Bulletin 24, 93-95.

Leonard HL, Swedo SE, Lenane MC, Rettew DC, Cheslow DL, Hamburger SD, Rapoport JL (1991). A double-blind desipramine substitution during long-term clomipramine treatment in children and adolescents with obsessivecompulsive disorder. Archives of General Psychiatry 48, 922-927.

Lopez-Ibor Jr. J, Saiz J, Cottraux J, Note I, Vinas R, Bourgeois M, Hernandez M, Gomez-Perez JC (1996). Double-blind comparison of fluoxetine versus clomipramine in the treatment of obsessive compulsive disorder. European Neuropsychopharmacology 6, 111-118.

Maina G, Albert U, Ziero S, Bogetto F (2003b). Antipsychotic augmentation for treatment-resistant obsessive compulsive disorder: what if antipsychotic is discontinued? International Clinical Psychopharmacology 18, 23-28.

Maina G, Salvi V, Bogettoa (2003a). Weight-gain during long-term drug treatment of obsessive compulsive disorder. European Neuopsychopharmacology 13 (Suppl.), S357.

March JS, Biederman J, Wolkow R, Safferman A, Mardekian J, Cook EH, Cutler NR, Dominguez R, Ferguson J, Muller B, Riesenberg R, Rosenthal M, Sallee FR, Wagner KD, Steiner H (1998). Sertraline in children and adolescents with obsessive compulsive disorder: a multicentre randomised controlled trial. Journal of the American Medical Association 28, 1752-1756.

March JS, Frances A, Kahn DA, Carpenter D (1997). The Expert Consensus Guideline series. Treatment of obsessive-compulsive disorder. Journal of Clinical Psychiatry 58 (Suppl.), 1-72.

Marks IM, Lelliott P, Basoglu M, Noshirvani H, Monteiro W, Cohen D, Kasvikis Y (1988). Clomipramine, self-exposure and therapist-aided exposure for obsessive-compulsive rituals. British Journal of Psychiatry 152, 522-534.

Marks IM, Stern RS, Mawson D, Cobb J, McDonald R (1980). Clomipramine and exposure for obsessivecompulsive rituals. British Journal of Psychiatry 136, 1-25.

Mataix-Cols D, Rauch SL, Manzo PA, Jenike MA, Baer L (1999). Use of factor-analysed symptom dimensions to predict outcome with serotonin reuptake inhibitors and placebo in the treatment of obsessive-compulsive disorder. American Journal of Psychiatry 156, 1409-1416.

Mavissakalian M, Turner SM, Michelson L, Jacob R (1985). Tricyclic antidepressants in obsessive-compulsive disorder: antiobsessional or antidepressant agents? II. American Journal of Psychiatry 142, 572-576.

McDougle CJ, Barr LC, Goodman WK, Pelton GH, Aronson SC, Anand A, Price LH (1995). Lack of efficacy of clozapine monotherapy in refractory obsessive-compulsive disorder. American Journal of Psychiatry 152, 423-429. 
McDougle CJ, Epperson CN, Pelton GH, Wasylink S, Price LH (2000). A double-blind, placebo-controlled study of risperidone addition in serotonin reuptake inhibitorrefractory obsessive-compulsive disorder. Archives of General Psychiatry 57, 794-801.

McDougle CJ, Goodman WK, Leckman JF, Holzer JC, Barr LC, McCance-Katz E (1993). Limited therapeutic effect of addition of buspirone in fluvoxamine-refractory obsessive compulsive disorder. American Journal of Psychiatry 150, 647-649.

McDougle CJ, Goodman WK, Leckman JF, Lee NC, Heninger GR, Price LH (1994). Haloperidol addition in fluvoxamine-refractory obsessive-compulsive disorder: a double-blind placebo-controlled study in patients with and without tics. Archives of General Psychiatry 51, 302-308.

McDougle CJ, Goodman WK, Price LH, Delgado PL, Krystal JH, Charney DS, Heninger GR (1990). Neuroleptic addition in fluvoxamine-refractory obsessive compulsive disorder. American Journal of Psychiatry 147, 652-654.

McDougle CJ, Price LH, Goodman WK, Charney DS, Heninger GR (1991). A controlled trial of lithium augmentation in fluvoxamine-refractory obsessive compulsive disorder: lack of efficacy. Journal Clinical of Psychopharmacology 11, 175-184.

McDougle CJ, Walsh KH (2001). Treatment of refractory OCD. In: Fineberg NA, Marazitti D, Stein D (Eds.), Obsessive Compulsive Disorder: A Practical Guide (pp. 135-152). London, UK: Martin Dunitz.

Metin O, Yaziki K, Tot S, Yazici AE (2003). Amisulpride augmentation in treatment-resistant obsessive compulsive disorder: an open trial. Human Psychopharmacology 18, 463-467.

Milanfranchi A, Ravagli S, Lensi P, Marazitti D, Cassano GB (1997). A double-blind study of fluvoxamine and clomipramine in the treatment of obsessive compulsive disorder. International Clinical Psychopharmacology 12, 131-136.

Monteiro WO, Noshirvani HF, Marks IM, Lelliott PT (1987). Anorgasmia from clomipramine in obsessive-compulsive disorder: a controlled trial. British Journal of Psychiatry 151, 107-112.

Montgomery SA (1980). Clomipramine in obsessional neurosis: a placebo-controlled trial. Pharmacological Medicine 1, 189-192.

Montgomery SA, Fineberg N, Montgomery DB (1990). The efficacy of serotonergic drugs in OCD: power calculations compared with placebo. In: Montgomery SA, Goodman WK, Goeting N (Eds.), Current Approaches in Obsessive Compulsive Disorder (pp. 54-63). Southampton, UK: Ashford Colour Press for Duphar Medical Relations.

Montgomery SA, Fineberg NA, Montgomery DB, Bullock T (1992). L-tryptophan in obsessive compulsive disorder: a placebo-controlled study. European Neuropsychopharmacology 2 (Suppl. 2), 384.

Montgomery SA, Kasper S, Stein DJ, Bang Hedegaard K, Lemming OM (2001). Citalopram $20 \mathrm{mg}, 40 \mathrm{mg}$, and $60 \mathrm{mg}$ are all effective and well tolerated compared with placebo in obsessive-compulsive disorder. International Clinical Psychopharmacology 16, 75-86.

Montgomery SA, McIntyre A, Osterheider M, Sarteschi P, Zitterl W, Zohar J, Birkett M, Wood AJ (1993). A doubleblind placebo-controlled study of fluoxetine in patients with DSM-IIIR obsessive compulsive disorder. European Neuropsychopharmacology 3, 143-152.

Montgomery SA, Montgomery DB (1980). Measurement of change in psychiatric illness: new obsessional, schizophrenia and depression scales. Postgraduate Medical Journal (Suppl.), 50-52.

Mundo E, Bareggi SR, Pirola R, Bellodi L (1999). Effect of acute intravenous clomipramine and antiobsessional response to proserotonergic drugs: is gender a predictive variable? Biological Psychiatry 45, 290-294.

Mundo E, Bareggi SR, Pirola R, Bellodi L, Smeraldi E (1997b). Long-term pharmacotherapy of obsessivecompulsive disorder; a double-blind controlled study. Journal of Clinical Psychopharmacology 17, 4-10.

Mundo E, Bianchi L, Bellodi L (1997a). Efficacy of fluvoxamine, paroxetine, and citalopram in the treatment of obsessive-compulsive disorder; a single-blind study. Journal of Clinical Psychopharmacology 17, 267-271.

Mundo E, Guglielmo E, Bellodi L (1998). Effect of adjuvant pindolol on the antiobsessional response to fluvoxamine; a double-blind, placebo-controlled study. International Clinical Psychopharmacology 13, 219-224.

Mundo E, Rouillon F, Figuera ML, Stigler M (2001). Fluvoxamine in obsessive-compulsive disorder: similar efficacy but superior tolerability in comparison with clomipramine. Human Psychopharmacology 16, 461-468.

Pallanti S, Hollander E, Bienstock C, Koran L, Leckman J, Marazziti D, Pato M, Stein D, Zohar J and the International Treatment-Refractory OCD Consortium (2002a). Treatment-non-response in OCD: methodological issues and operational definitions. International Journal of Neuropsychopharmacology 5, 181-191.

Pallanti S, Quercioli L, Koran LM (2002b). Citalopram infusions in resistant obsessive compulsive disorder: an open trial. Journal of Clinical Psychiatry 63, 796-801.

Pallanti S, Quercioli L, Paiva RS, Koran LM (1999). Citalopram for treatment-resistant obsessive-compulsive disorder. European Psychiatry 14, 101-106.

Pato MT, Zohar-Kadouch R, Zohar J (1988). Return of symptoms after discontinuation of clomipramine in patients with obsessive compulsive disorder. American Journal of Psychiatry 145, 211-214.

Perlmutter SJ, Leitman SF, Garvey MH, Hamburger S, Feldman E, Leonard HL, Swedo SE (1999). Therapeutic plasma exchange and intravenous immunoglobulin for obsessive compulsive disorder and tic disorders in children. Lancet 354, 1153-1158.

Perse T, Greist JH, Jefferson JW, Rosenfeld R, Dar R (1987). Fluvoxamine treatment of obsessive compulsive disorder. American Journal of Psychiatry 144, 1543-1548.

Piccinelli M, Pini S, Bellantuono C, Wilkinson G (1995). Efficacy of drug treatment in obsessive compulsive disorder. British Journal of Psychiatry 166, 424-443. 
Pidrman V, Tuma I (1998). Citalopram versus clomipramine in double-blind therapy of obsessive compulsive disorder. Abstracts 11th Congress European College of Neuropsychopharmacology, 31 Oct. -4 Nov., Paris.

Pigott TA, L'Heureux F, Dubbert B, Bernstein S, Murphy DL, Greist JH, Tollefson G, Rasmussen S, McElroy SL, Dominguez RA, Jenike MA (1994). Obsessive compulsive disorder: comorbid conditions. Journal of Clinical Psychiatry 55 (Suppl.), 15-32.

Pigott TA, L'Heureux F, Hill JL, Bihari K, Bernstein SE, Murphy DL (1992a). A double-blind study of adjuvant buspirone hydrochloride in clomipramine-treated patients with obsessive compulsive disorder. Journal of Clinical Psychopharmacology 12, 11-18.

Pigott TA, L'Heureux F, Rubinstein CF, Hill JL, Murphy DL (1992b). A controlled trial of clonazepam augmentation in OCD patients treated with clomipramine or fluoxetine. New Research Abstracts NR 144 presented at the 145th Annual Meeting of the American Psychiatric Association, Washington, DC, USA.

Pigott TA, Pato MT, Bernstein SE, Grover GN, Hill JL, Tolliver TJ, Murphy DL (1990). Controlled comparisons of clomipramine and fluoxetine in the treatment of obsessive compulsive disorder. Behavioral and biological results. Archives of General Psychiatry 47, 926-932.

Pigott TA, Pato MT, L'Heureux F, Hill JL, Grover GN, Bernstein SE, Murphy DL (1991). A controlled comparison of adjuvant lithium carbonate or thyroid hormone in clomipramine-treated patients with obsessive compulsive disorder. Journal of Clinical Psychopharmacology 11, 242-248.

Pigott TA, Seay SM (1999). A review of the efficacy of selective serotonin reuptake inhibitors in obsessive compulsive disorder. Journal of Clinical Psychiatry 60, 101-106.

Rasmussen SA, Eisen JL (1990). Epidemiology of obsessive compulsive disorder. Journal of Clinical Psychiatry 51, 10-13.

Rasmussen S, Hackett E, Duboff E, Greist J, Halaris A, Koran LM, Liebowitz M, Lydiard RB, McElroy S, Mendels J, O'Connor K (1997). A 2-year study of sertraline in the treatment of obsessive-compulsive disorder. International Clinical Psychopharmacology 12, 309-316.

Ravizza L, Albert U, Ceregato A (2001). Venlafaxine in OCD. Presented at the International Obsessive Compulsive Disorder Conference, Sardinia, Italy.

Ravizza L, Maina G, Bogetto F, Albert U, Barzega G, Bellino S (1998). Long term treatment of obsessive compulsive disorder. CNS Drugs 10, 247-255.

Reynghe de Voxrie GV (1968). Anafranil (G34586) in obsessive neurosis. Acta Neurologia Belgica 68, 787-792.

Riddle MA, Reeve EA, Yaryura-Tobias J, Yang HM, Claghorn JL, Gaffney G, Greist JH, Holland D, McConville BJ, Pigott T, Walkup JT (2001). Fluvoxamine for children and adolescents with obsessive compulsive disorder; a randomised, controlled multicentre trial. Journal of the American Academy of Child and Adolescent Psychiatry 40, 222-229.
Riddle MA, Scahill L, King RA, Hardin MT, Anderson GM, Ort SI, Smith JC, Leckman JF, Cohen DJ (1992). Doubleblind crossover trial of fluoxetine and placebo in children and adolescents with obsessive compulsive disorder. Journal of the American Academy of Child and Adolescent Psychiatry 31, 1062-1069.

Robins LN, Helzer JE, Weissman MM, Orvaschel H, Gruenberg E, Burke Jr. JD, Regier DA (1984). Lifetime prevalence of specific psychiatric disorders in three sites. Archives of General Psychiatry 41, 949-958.

Romano S, Goodman WK, Tamura R, Gonzales J, Deltito J, DuPont R, Hertzman M, Burnie G, Jenike M, Landbloom R, Pigott T, Shear K, Stahl S, Stewart R, Zajecka J (2001). Long-term treatment of obsessive-compulsive disorder after an acute response: a comparison of fluoxetine versus placebo. Journal of Clinical Psychopharmacology 21, 46-52.

Rosenbaum JF, Fava M, Hoog S, Ascroft RC, Krebs WB (1998). Selective serotonin reuptake inhibitor discontinuation syndrome; a randomised clinical trial. Biological Psychiatry 44, 77-87.

Rouillon F (1998). A double-blind comparison of fluvoxamine and clomipramine in OCD. European Neuropsychopharmacology 8 (Suppl.), 260-261.

Sevincok L, Topuz A (2003). Lack of efficacy of low dose quetiapine addition in refractory obsessive compulsive disorder. Journal of Clinical Psychopharmacology 23, 448-450.

Sheehan DV, Harnett-Sheehan K, Raj BA (1996). The measurement of disability. International Clinical Psychopharmacology 11 (Suppl.), 89-95.

Smeraldi E, Ergovesi S, Bianchi I (1992). Fluvoxamine versus clomipramine treatment in obsessive-compulsive disorder: a preliminary study. New Trends in Experimental and Clinical Psychiatry 8, 63-65.

Stein D, Montgomery SA, Kasper S, Tanghoj P (2001). Predictors of response to pharmacotherapy with citalopram in obsessive compulsive disorder. International Clinical Psychopharmacology 16, 357-361.

Stein DJ, Spadaccini E, Hollander E (1995). Meta-analysis of pharmacotherapy trials of obsessive compulsive disorder. International Clinical Psychopharmacology 10, $11-18$.

Szegedi A, Wetzel H, Leal M, Hartter S, Hiemke C (1996). Combination treatment with clomipramine and fluvoxamine: drug monitoring, safety and tolerability data. Journal of Clinical Psychiatry 57, 257-264.

Tenney NH, Denys DA, Van Megen HJGM, Glas G, Westenberg HGM (2003). Effect of a pharmacological intervention on quality of life in patients with obsessivecompulsive disorder. International Clinical Psychopharmacology 18, 29-33.

Thoren P, Asberg M, Cronholm B, Jornestedt L, Traskman L (1980). Clomipramine treatment and obsessive compulsive disorder. Archives of General Psychiatry 37, 1281-1285.

Tollefson G, Rampey A, Potvin J, Jenike MA, Rush AJ, Dominquez RA, Koran LM, Shear MK, Goodman W, Genduso LA (1994). A multicenter investigation of fixed-dose fluoxetine in the treatment of obsessive 
compulsive disorder. Archives of General Psychiatry 51, 559-567.

Ushijima S, Kamijima K, Asai M, Murasaki M, Nakajima T, Kudo Y, Tashiro N, Kurihara M, Miura S (1997). Clinical evaluation of sertraline hydrochloride, a selective serotonin reuptake inhibitor, in the treatment of obsessivecompulsive disorder: a double blind placebo-controlled trial. Japanese Journal of Neuropsychopharmacology 19, 603-623.

Vallejo J, Olivares J, Marcos TI, Bulbena A, Menchon JM (1992). Clomipramine versus phenelzine in obsessive compulsive disorder: a controlled clinical trial. British Journal of Psychiatry 161, 665-670.

Volavka J, Neziroglu F, Yaryura-Tobias JA (1985). Clomipramine and imipramine in obsessive compulsive disorder. Psychiatry Research 14, 85-93.

Wagner KD, March J, Landau P (1999). Safety and efficacy of sertraline in long-term paediatric OCD treatment: a multicentre study. Presented at the 39th Annual Meeting of the New Clinical Drug Evaluation Unit, FL, USA.

Wheadon D, Bushnell W, Steiner M (1993). A fixed dose comparison of 20,40 or $60 \mathrm{mg}$ paroxetine to placebo in the treatment of obsessive compulsive disorder. Poster presented at Annual Meeting of the American College of Neuropsychopharmacology, Honolulu, Hawaii, USA.
Weissman MM, Bland RC, Canino GJ, Greenwald S, Hwu HG, Chung-Kyoon-Lee, Newman SC, Oakley-Browne MA, Rubio-Stipec M, Wickramaratne PJ, Wittchen HU, Yeh EK (1994). The cross national epidemiology of obsessive compulsive disorder. Journal of Clinical Psychiatry 55 (Suppl.), 5-10.

Wilens TE, Biederman J, March J, Wolkow R, Fine CS, Millstein RB, Faraone SV, Geller D, Spencer TJ (1999). Absence of cardiovascular and adverse effects of sertraline in children and adolescents. Journal of American Academy of Child and Adolescent Psychiatry 38, 573-577.

Wood A, Tollefson GD, Burkitt M (1993). Pharmacotherapy of obsessive compulsive disorder: experience with fluoxetine. International Clinical Psychopharmacology 8, 301-306.

Yaryura-Tobias JA, Neziroglu FA (1996). Venlafaxine in obsessive compulsive disorder. Archives of General Psychiatry 53, 653-654.

Yaryura-Tobias JA, Neziroglu F, Bergman L (1976). Clomipramine for obsessive-compulsive neurosis: an organic approach. Current Therapeutics Research 20, 541-548.

Zohar J, Judge R (1996). Paroxetine versus clomipramine in the treatment of obsessive compulsive disorder. British Journal of Psychiatry 169, 468-474. 